\title{
$\begin{array}{ll}\text { Research Square } & \text { Preprints are preliminary reports that have not undergone peer review. } \\ \text { They should not be considered conclusive, used to inform clinical practice, } \\ \text { or referenced by the media as validated information. }\end{array}$
}

\section{Knockdown of PC4 Increases Chemosensitivity of Oxaliplatin in Triple Negative Breast Cancer by Supressing mTOR Pathway}

\section{Qing Wang}

Southwest Medical University

\section{Le Ma}

Third Military Medical University: Army Medical University

\section{Long Chen}

Third Military Medical University: Army Medical University

\section{Hongdan Chen}

Third Military Medical University: Army Medical University

\section{Min Luo}

Third Military Medical University: Army Medical University

\section{Wei Yang}

Southwest Medical University

\section{Fengying Liao}

Third Military Medical University: Army Medical University

\section{Qiang Gong}

Third Military Medical University: Army Medical University

\section{Yang Wang}

Third Military Medical University: Army Medical University

\section{Zeyu Yang}

Third Military Medical University: Army Medical University Jie Wu

Third Military Medical University: Army Medical University

Can Zhang

Third Military Medical University: Army Medical University

Jiancheng Zheng

Third Military Medical University: Army Medical University

\section{Shiqian Han}

Third Military Medical University: Army Medical University

\section{Yu Leng}

Third Military Medical University: Army Medical University

Peng Luo 
Third Military Medical University: Army Medical University

Shi Chunmeng ( $\nabla$ shicm@tmmu.edu.cn)

Institute of Rocket Force Medicine https://orcid.org/0000-0002-8264-738X

\section{Research}

Keywords: Triple negative breast cancer, Positive cofactor 4, Mammalian target of rapamycin, Oxaliplatin, Chemosensitivity

Posted Date: November 10th, 2020

DOl: https://doi.org/10.21203/rs.3.rs-101235/v1

License: (9) This work is licensed under a Creative Commons Attribution 4.0 International License. Read Full License 


\section{Abstract}

Background: The response to chemotherapy is an important factor in the prognosis of patients with triple negative breast cancer (TNBC). Human positive coactivator 4 (PC4) is a multifunctional nuclear protein, that is highly expressed in various tumors including breast cancer and shows a potential role in cancer development and progression. However, the role of PC4 in chemotherapeutic responses of TNBC remains unclear. Our work aim to identify the role of PC4 in the response to oxaliplatin (Oxa) of TNBC patients.

Results: We found that PC4 is significantly upregulated in TNBC cells compared with non-TNBC cells, implying its potential role in TNBC. Then, in vivo and in vitro studies revealed that knockdown of PC4 increased chemosensitivity of Oxa in TNBC by supressing mTOR pathway.

Conclusions: Our findings demonstrated the signatures of PC4 in the chemotherapeutic response of TNBC, and indicated that PC4 might be a promising therapeutic target for TNBC.

\section{Background}

Breast cancer is one of the most common cancers with extremely high incidence and mortality among women [1], of which TNBC accounts for about 10-20\% [2]. TNBC is the type of breast cancer with negative expression of estrogen receptor (ER), progesterone receptor (PR) and human epidermal growth factor receptor 2 (HER2). Compared with non-TNBC, the growth and the incidence of local recurrence and distant metastasis in TNBC is markedly increased. Due to lack of effective endocrine and targeted therapy and chemoresistance, the prognosis of TNBC is poor $[3,4]$. However, their underlying molecular mechanisms are still largely unknown.

Mammalian target of rapamycin (mTOR) is a conserved serine/threonine protein kinase, its activation initiated a biosynthesis cascade to support anabolism and cell proliferation, symbolized the cell to a "growth" state $[5,6]$. Recent studies have also shown the abnormal activation of the mTOR pathway in drug resistance and relapse, including Oxa resistance [7-9]. And, mTOR inhibitors (such as rapamycin and its analogues) could repress cancer growth and progression [10-12], implying a potential role of mTOR as a therapeutic target. Compared with non-TNBC, mTOR hyperactivity was frequently observed in TNBC and was correlated with poor prognosis $[13,14]$. However, TNBC patients eventually developed resistance to mTOR inhibitors and had adverse outcomes $[11,15]$. Thus, it is necessary to clarify the role and molecular mechanisms of mTOR in TNBC progression and identify highly tumor-selective upstream targets of mTOR to improve TNBC patients' outcomes.

Positive cofactor 4 (PC4), also known as SUB1, was a highly conserved and multifunctional nuclear protein which is involved in various molecular biological processes $[16,17]$, including basic transcription $[18,19,21]$, DNA replication [22-24], DNA repair [25-27] and chromatin organization [28, 29]. Recent studies have shown that PC4 was highly expressed in various tumors and played oncogenic roles, included lung cancer [30], astrocytoma [31], prostate cancer [32,33] and esophageal squamous cell carcinoma [27]. In addition, our previous study found that PC4 was upregulated in breast cancer and 
positively correlated with cancer development and progression [10]. However, the role of PC4 in TNBC progression and chemotherapeutic response remain unclear.

In this study, our results showed that the expression level of PC4 in TNBC cells was higher than that in non-TNBC cells. And knockdown of PC4 increased chemosensitivity of Oxa in TNBC by suppressing mTOR pathway. Taken together, these results suggested that PC4 might be a promising therapeutic target for TNBC.

\section{Results}

PC4 is significantly upregulated in TNBC cells.

To validate the expression level of PC4 in TNBC and none-TNBC, the expression of PC4 in two TNBC cell lines (MDA-MB-231, MDA-MB-453) and two non-TNBC cell lines (MDA-MB-361, SK-BR-3) were analyzed. Firstly, the results of qPCR showed that the mRNA expression level was significantly upregulated in the TNBC cell lines (Fig. 1a). Further, the results of Western Blot and Immunofluorescent Staining of PC4 also confirmed that higher PC4 protein level was also higher expressed in TNBC cells than that in non-TNBC cells (Fig. 1b and 1c). These results indicated that PC4 is significantly upregulated in TNBC cells, suggesting it might play an important role in the progression of TNBC breast cancer.

\section{Knockdown of PC4 significantly enhanced the chemosensitivity of TNBC cells to Oxa in vitro}

The response to chemotherapy is an important factor in the prognosis of TNBC patients. Our previous studies have shown that PC4 promote the cancer progression in multiple tumors [27, 30-33], but whether PC4 affects the chemotherapeutic response is still unknown. To elucidate this issue, PC4 in two TNBC cell lines (MDA-MB-231 and MDA-MA-453) was knocked down using two different lentiviruses by specific shRNAs to establish two stable cell lines, (Fig. 2a and 2b), and used for the subsequent loss-of-function study. Then Oxa, a common chemotherapeutic agent for TNBC patients, was used to study the effects of PC4 on the chemosensitivity of TNBC cells. Interestingly, the cell viability assays showed that PC4 knockdown enhanced the growth-inhibitory effect of TNBC cells with different Oxa treatment (Fig. 2c). Besides, PC4 knockdown also inhibited the colony formation ability in two TNBC cells after Oxa treatment (Fig. 2d and 2e). To further investigate the chemosensitivity of PC4, apoptosis detection by flow cytometry was performed $48 \mathrm{~h}$ after Oxa treatment. Our results showed that PC4 knockdown further promoted the Oxa-induced apoptosis in two TNBC cells (Fig. $2 \mathrm{f}$ and $2 \mathrm{~g}$ ). In addition, the results of the Hoechst staining and Western Blot also confirmed the phenomenon that more apoptosis was detected in two PC4 knockdown TNBC cells after Oxa treatment (Fig. 2h and 2i). These results indicate that knockdown of PC4 enhances the chemosensitivity of TNBC cells in vitro, suggesting that PC4 might play an important role in chemotherapeutic resistance of TNBC cells.

\section{Knockdown of PC4 sensitized MDA-MB-231 cells to Oxa in vivo}


To further investigate the effect of PC4 knockdown on chemosensitivity of TNBC cells in vivo, we established a nude mouse xenograft tumor model with PC4 knockdown or control TNBC cells. Our results showed that $5 \mathrm{mg} / \mathrm{kg}$ of Oxa via intraperitoneal injection every three days has no significant effect on the weight of the mice(Fig. 3a), however, PC4 knockdown tumors exhibited stronger growth inhibition to Oxa chemotherapy, since the slower tumor growth (Fig. 3b), smaller (Fig. 3c) and lighter tumor xenografts (Fig. 3d) were observed in PC4 knockdown TNBC cells compared to the control group after Oxa therapy. In addition, more apoptotic cells were also observed in PC4 knockdown tumors compared to the control group after Oxa treatment, which was detected by immunofluorescence staining of TUNEL (Fig. 3e and 3f) and cleaved caspase 3 (Fig. $3 \mathrm{~g}$ and $3 \mathrm{~h}$ ). These results indicate that PC4 knockdown also chemosensitises the TNBC cells.

\section{Inhibition of PC4 synergized TNBC to Oxa through mTOR pathway}

mTOR pathway is closely associated with chemotherapeutic resistance of TNBC, then we investigate whether chemosensitivity of PC4 knockdown is related to mTOR pathway. Interestingly, our data showed that PC4 knockdown significantly downregulated the level of mTOR's phosphorylation in two TNBC cells (Fig. 4a) and tumor xenografts (Fig. 4b and 4c). Then, further studies showed that MHY1485, an effective mTOR agonist, rescued the down-regulated mTOR signaling, and more importantly, reversed the growthinhibitory effects (Fig. 4e-g) and pro-apoptotic effects (Fig. 5a-e) of PC4 knockdown in two TNBC cells. These results indicate that PC4 knockdown enhances the chemosensitivity of TNBC cells by downregulating mTOR signaling.

\section{Discussion}

Up to now, cytotoxic chemotherapy is still the standard therapy for TNBC [4], since TNBC is unresponsive to hormone or targeted therapy which require positive receptors including HER2, ER or PR. However, the chemotherapeutic resistance and normal tissue toxicity limit the use of the tumor-killing dosage of chemotherapeutic drugs, resulting in the poor prognosis of TNBC [34]. Worse still, there are few effective targets to chemosensitise the TNBC. Our previous study has identified that PC4 was highly expressed in breast cancer, maintaining the malignant phenotype of breast cancer [10]. Interestingly, in this study, we found that higher PC4 level in TNBC cells than that in none-TNBC cells, and PC4 knockdown enhance the chemosensitivity of TNBC cells to Oxa both in vitro and in vivo, suggesting that PC4 is a potential therapeutic target for chemotherapeutic resistance of TNBC.

As a transcription cofactor, PC4 is involved in a variety of biological processes. Recent studies have found that PC4 also plays a role in embryonic development [23], skin wound healing [35], and radiotherapy sensitivity $[27,36]$. In this study, the expression level of PC4 in TNBC cell lines is higher than that in other breast cancer subtypes' cell lines, and downregulation of PC4 inhibited cell proliferation, and promoted cell apoptosis induced by Oxa through decreasing the expression of p-mTOR, p-4EBP1 and pS6RP. In addition, pretreatment with a specific mTOR activator (MHY1485) significantly neutralized the pro-apoptotic activity of knocking down PC4, demonstrating the important role of m-TOR in this process. 
In the past few decades, it has been reported that the overactivation of mTOR was related to Oxa resistance [7-9]. However, the specific mechanism of drug resistance was unclear. In this work, we have proved that PC4 may be the upstream to regulate mTOR, and targeting PC4 can improve the sensitivity of TNBC to Oxa and provide a novel insight for the treatment of TNBC. Unfortunately, we have no evidence yet that PC4 directly regulates mTOR.

\section{Conclusion}

Our study reveals for the first time that the expression level of PC4 in TNBC cell lines is higher than that in other breast cancer subtypes' cell lines and downregulation of PC4 increase chemosensitivity of Oxa in TNBC by supressing mTOR pathway which may offer a promising new approach in the effective treatment of TNBC.

\section{Methods}

\section{Animals and Cell lines}

Athymic female nude mice (4 weeks) were obtained from HUNAN SJA LABORATORY ANIMAL CO.,LTD and housed under specific pathogen-free conditions. Animal experiments followed the Guidelines for the Care and Use of Laboratory Animals of the TMMU, and all procedures were approved by the Animal Care and Use Committee of the TMMU. The human breast cancer cell lines (SK-BR-3, MDA-MB-361, MDA-MB231, MDA-MB-453) were purchased from the American Type Culture Collection (ATCC, USA) and the Cell Bank of the Chinese (Shanghai, China). All cells were cultured in DMEM medium (Hyclone, USA), supplemented with 10\% FBS (Biological Industries, USA) and 1\% streptomycin/penicillin (Beyotime, Shanghai, China), and incubated in $5 \% \mathrm{CO}_{2}$ at $37^{\circ} \mathrm{C}$.

\section{Drug treatment of cells}

Oxa (Oxa, S1224) used in the experiment was purchased from Selleck Chemicals Company (USA). For mice, Oxa or PBS was given through intraperitoneal injection at $5 \mathrm{mg} / \mathrm{kg}$ every three days when the tumor volume reaches $75 \mathrm{~mm}^{3}$ for two weeks. In vitro studies, MDA-MB-231 cells were treated with $20 \mu \mathrm{M}$ and MDA-MB-453 cells were treated with $15 \mu \mathrm{M}$ Oxa for $48 \mathrm{~h}$ and then incubated in drug-free medium. MHY1485 was purchased from Selleck Chemicals Company (USA), which was used to incubate $1 \mu \mathrm{M}$ for $24 \mathrm{~h}$ before Oxa treatment.

\section{Cell proliferation assay and colony formation assay}

The cells were seeded into 96-well plates with a density of 4000 cells each well and $100 \mu$ l medium. After the cells had attached to the wall, the cells were washed twice using PBS, and added with Oxa at gradient concentrations $(0 \mu \mathrm{M}, 5 \mu \mathrm{M}, 10 \mu \mathrm{M}, 15 \mu \mathrm{M}, 20 \mu \mathrm{M}$, and $40 \mu \mathrm{M}, 60 \mu \mathrm{M})$. Afterwards, the cells were cultured in a cell incubator for $48 \mathrm{~h}$. The supernatant was discarded after incubation, and $110 \mu \mathrm{l}$ of Cell counting kit-8 (CCK-8) (CK04, DOJINDO, Japan) working solution ( $\left.\mathbf{V}_{\text {culture medium }}: \mathbf{V}_{\text {CCK-8 stock solution }}=10: 1\right)$ was 
added to each well to continue the culture for $3 \mathrm{~h}$. The OD value of each well was read using a DG-3022A microplate reader (Nanjing Huadong Electron Tube Factory, China) at $450 \mathrm{~nm}$ to calculate relative cell viability (\%) (relative cell viability = cell viability of drug-feed wells/the cell viability of drug-free wells), and further fitted to a dose-response curve in Graphpad Prism 8 software. To determine their clonogenic ability, MDA-MB-231 and MDA-MB-453 cells were trypsinized and seeded in 6-well plates (1000 cells per well). After the cells had attached to the wall, the cells were washed twice using PBS, and added with Oxa. The medium was changed every three days, and cells were cultured for up to 14 days until colonies were clearly visible. At the endpoint, cells were washed twice with PBS, fixed with $4 \%$ paraformaldehyde for 15 minutes, stained with crystal violet (Beyotime, China) for 30 minutes, and then colonies with $>50$ cells were counted.

\section{RNA Interference:}

The shRNAs targeting human PC4 were purchased and constructed by GenePharma (Shanghai, China). According to the manufacturer's protocol, MDA-MB-231 and MDA-MB-453 cells were transfected with shRNAs or plasmid according to the manufactures' instructions. The transfected cells were labeled as shPC4-1 and shPC4-2. The detailed sequence of shRNA listed in supplementary materials Table 1

\section{Western Blotting analysis}

The cells were harvested, washed, and lysed with RIPA buffer (Beyotime, China) containing protease inhibitor cocktail (Roche) for 30 minutes on ice. Total protein was extracted, and quantitated by a BCA kit (Beyotime, China) according to the manufacturer's instruction. The protein samples were separated by electrophoresis in 10\% 12\% gel, and then transferred onto PVDF membranes (Millipore). Blotted membranes were blocked and incubation with primary antibodies overnight at $4{ }^{\circ} \mathrm{C}$. The membranes were washed 5 minutes for 3 times with TBST, and subsequently incubated $1 \mathrm{~h}$ with HRP-linked secondary antibody (Cell Signaling Technology, USA) at room temperature. The band intensities were visualized and detected by an enhanced chemiluminescence detection system (Bio-Rad Laboratories). Besides, the detailed information of primary antibody is shown in supplementary Table 3.

\section{Quantitative RT-PCR}

Total RNA was extracted from breast cancer cells using Trizol (Cwbiotech, China). $1 \mu \mathrm{g}$ RNA was reverse transcribed into cDNA using the RevertAid First Strand cDNA Synthesis kit (\#K1622, Thermo Fisher Scientific, Inc.) according to the manufacturer's protocol. As described in our previous work, RT-qPCR was performed using a SYBR Green qPCR master mix (Takara) according to the manufacturer's protocol. After the reactions were completed, the comparative threshold cycle (Ct) method was used to calculate the relative gene expression. expression was used as the internal control. The utilized primer sequence for real-time qPCR listed in supplementary Table 2.

\section{Flow cytometry}


Apoptosis was evaluated by an Annexin V-APC apoptosis detection kit (BD Biosciences). Briefly, cells were collected, washed twice with PBS and resuspended in $500 \mu \mathrm{l}$ of binding buffer. Subsequently, the cells were stained with $5 \mu \mathrm{l}$ of Annexin V-APC and $5 \mu \mathrm{l}$ of PI, then incubated for 15 minuets in the dark. The percentage of apoptotic cells was detected by flow cytometry. Experiments were performed at least three times.

\section{Hoechst staining}

Replicate cultures of $1 \times 10^{6}$ cells per well were plated in a 24-well plate. After Oxa treatment, the cells were incubated with $1 \mu \mathrm{l}$ of Hoechst 33342 1000x (C0081S-6, Beyotime) and $1 \mathrm{ml}$ PBS solution per well at $37^{\circ} \mathrm{C}$ for 10 minutes, followed by observation under a fluorescence microscope. Strong fluorescence can be observed in the nuclei of apoptotic cells, while weak fluorescence was observed in non-apoptotic cells.

\section{TUNEL assay}

For tissue section, the paraffin-embedded sections were dewaxed, rehydrated and add $20 \mu \mathrm{g} / \mathrm{mL}$ DNase free Proteinase $\mathrm{K}$ (ST533, Beyotime) at $37^{\circ} \mathrm{C}$ for 20 minutes. For vitro experiments, the cells were cultured in 48-well plates, incubated $24 \mathrm{~h}$, then goes through a series of treatments, then fixed in $4 \%$ paraformaldehyde and permeabilized in 0.3\% Triton X-100. Then, a One Step TUNEL Apoptosis Assay Kit (C1090, Beyotime) was performed according to the manufacturer's instructions and observed under a fluorescence microscope (Leica, DMi8, Wetzlar, Germany).

\section{Tumorigenicity assays}

Mice were inoculated subcutaneously with $5 \times 10^{6}$ respective MDA-MB-231 cells with stable PC4 knockdown or control cells in $100 \mu \mathrm{l}$ PBS at one dorsal site. Meanwhile, these mice were divided into four groups randomly (Control, $n=5$; Control+Oxa, $n=5$; shPC4-1, $n=5$; shPC4-1+0xa, $n=5$ ). Tumor growth was grossly monitored and measured with sliding calipers every 3 days. Volume of tumors were calculated according to the formula: volume $\left(\mathrm{mm}^{3}\right)=$ (width ${ }^{2} \mathrm{x}$ length)/2. Oxa or PBS was given through intraperitoneal injection at $5 \mathrm{mg} / \mathrm{kg}$ every three days when the tumor volume reaches $75 \mathrm{~mm}^{3}$ for two weeks, weight changes were recorded during the drug treatment. Then the mice were sacrificed, and the xenograft tumors were dissected, weighed and fixed in $4 \%$ paraformaldehyde for subsequent experiment.

\section{Immunofluorescence}

Paraffin-embedded tissue sections were dewaxed, rehydrated and immersed in Sodium citrate repair solution ( $\mathrm{pH} 6.0$ ) for 15 minutes at $98^{\circ} \mathrm{C}$ for antigen retrieval. The slides were incubated with primary antibody overnight at $4^{\circ} \mathrm{C}$. The slides were washed thrice with PBS (5 minutes each time), incubated with the appropriate secondary antibody for $1 \mathrm{~h}$ at $37^{\circ} \mathrm{C}$ and then detected by fluorescence microscope (Olympus BX51). The ratio of target protein-positive cells to DAPI-positive cells in Random field o per group was used for quantification by ImageJ software.

\section{Statistical analysis}


the results of this research are presented as the means \pm standard. The data were analyzed in Excel, GraphPad 8.0 and SPSS 25.0 (IBM, Chicago, IL, USA). Comparisons between two groups were performed using the Student's t-test. Comparisons among three or more groups were performed using a one-way analysis of variance (ANOVA). $P<0.05$ indicated a statistically significant difference.

\section{Abbreviations}

PC4: positive cofactor 4; TNBC: triple negative breast cancer; Oxa: Oxaliplatin; ER: estrogen receptor; ER: progesterone receptor; HER2:human epidermal growth factor receptor 2; CCK8: Cell counting kit-8; qPCR: quantitative polymerase chain reaction; PARP: Poly ADP-ribose Polymerase; C-caspase 3: Cleaved caspase 3; C-caspase 9:Cleaved caspase 9; p-mTOR :Phospho-mTOR; t-4EBP1: Total Eukaryotic Translation Initiation Factor 4E-Binding Protein 1; p-4EBP1: Phospho- Eukaryotic Translation Initiation Factor 4E-Binding Protein 1; p-S6RP: Phospho-S6 Ribosomal Protein

\section{Declarations}

\section{Acknowledgements}

Not applicable.

\section{Authors' contributions}

QW performed the mostly experiments, analyzed the data, drafted the manuscript; LM performed the Western Blot, edited the manuscript; $L C$ took part in animal immunofluorescence, edited the manuscript; $\mathrm{HC}, \mathrm{ML}, \mathrm{WY}$ and $\mathrm{CZ}$ took part in animal experiments; FL, QG, YW, YY, JW, JZ, SH and YL participated in cellular and molecular biology experiments (RNAi, qPCR, Flow cytometry). PL contributed to helpful discussion and reviewed the manuscript. CS designed the study, supervised the experiments and revised the manuscript. All authors have read and approved the final manuscript.

\section{Funding}

This work was supported by Key Program of National Natural Science Foundation (82030056) and University Innovation Team Building Program of Chongqing (CXTDG201602020).

\section{Availability of data and materials}

The datasets generated and analyzed during the current study are available from the corresponding author on reasonable request.

\section{Ethics approval and consent to participate}

All the mouse experiments were approved by the Institutional Animal Care and Use Committee of the Third Military Medical University and carried out in accordance with the "Guide for the care and use of 
laboratory animals" published by the US National Institutes of Health (Publication no.85-23, revised 1996).

\section{Consent for publication}

Not applicable.

\section{Competing interests}

The authors declare that they have no competing interests.

\section{Author details}

${ }^{1}$ Department of Oncology, The Affiliated Hospital of Southwest Medical University, Luzhou 646000 , China

${ }^{2}$ Institute of Rocket Force Medicine, State Key Laboratory of Trauma, Burns and Combined Injury, Third Military Medical University, Chongqing 400038, China

${ }^{3}$ Department of Hematology, Southwest Hospital, Third Military Medical University, Chongqing 40038, China

${ }^{4}$ Department of Breast and Thyroid Surgery, Chongqing General Hospital, University of Chinese Academy of Sciences, Chongqing 401121, China

${ }^{5}$ Key Laboratory of Environmental Pollution Monitoring and Disease Control, Ministry of Education, School of Public Health, Guizhou Medical University, Guiyang 550025, China

${ }^{6}$ Institute of Tropical Medicine, Third Military Medical University, Chongqing 400038, China

7 Department of Ophthalmology, The Third Affiliated Hospital of Chongqing Medical University (Gener Hospital), Chongqing 401120, China

* Corresponding auther『Chunmeng Shi, shicm@tmmu.edu.cn; Peng Luo, Email: luopeng2008@126.com

† These authors contributed equally to this work.

\section{References}

1. Siegel RL, Miller KD, Jemal A. Cancer statistics, 2019. CA Cancer J Clin. 2019;69(1):7-34.

2. Morris GJ, Naidu S, Topham AK, Guiles F, Xu Y, McCue P, Schwartz GF, Park PK, Rosenberg AL, Brill K, et al. Differences in breast carcinoma characteristics in newly diagnosed African-American and Caucasian patients: a single-institution compilation compared with the National Cancer Institute's Surveillance, Epidemiology, and End Results database. Cancer. 2007;110(4):876-84. 
3. Yin L, Duan JJ, Bian XW, Yu SC. Triple-negative breast cancer molecular subtyping and treatment progress. Breast Cancer Res. 2020;22(1):61.

4. Gluz O, Liedtke C, Gottschalk N, Pusztai L, Nitz U, Harbeck N. Triple-negative breast cancer-current status and future directions. Ann Oncol. 2009;20(12):1913-27.

5. Mossmann D, Park S, Hall MN. mTOR signalling and cellular metabolism are mutual determinants in cancer. Nat Rev Cancer. 2018;18(12):744-57.

6. Liu GY, Sabatini DM. mTOR at the nexus of nutrition, growth, ageing and disease. Nat Rev Mol Cell Biol. 2020;21(4):183-203.

7. Li N, Zhang Z, Jiang G, Sun H, Yu D. Nobiletin sensitizes colorectal cancer cells to oxaliplatin by PI3K/Akt/MTOR pathway. Front Biosci (Landmark Ed). 2019;24:303-12.

8. Zhang Y, Xie C, Li A, Liu X, Xing Y, Shen J, Huo Z, Zhou S, Liu X, Xie Y, et al. PKI-587 enhances chemosensitivity of oxaliplatin in hepatocellular carcinoma through suppressing DNA damage repair pathway (NHEJ and HR) and PI3K/AKT/mTOR pathway. Am J Transl Res. 2019;11(8):5134-49.

9. Lu M, Zessin AS, Glover W, Hsu DS. Activation of the mTOR Pathway by Oxaliplatin in the Treatment of Colorectal Cancer Liver Metastasis. PLoS One. 2017;12(1):e0169439.

10. Luo P, Zhang C, Liao F, Chen L, Liu Z, Long L, Jiang Z, Wang Y, Wang Z, Liu Z, et al. Transcriptional positive cofactor 4 promotes breast cancer proliferation and metastasis through c-Myc mediated Warburg effect. Cell Commun Signal. 2019;17(1):36.

11. Hua $\mathrm{H}$, Kong Q, Zhang H, Wang J, Luo T, Jiang Y. Targeting mTOR for cancer therapy. J Hematol Oncol. 2019;12(1):71.

12. Li J, Kim SG, Blenis J. Rapamycin: one drug, many effects. Cell Metab. 2014;19(3):373-9.

13. Walsh S, Flanagan L, Quinn C, Evoy D, McDermott EW, Pierce A, Duffy MJ. mTOR in breast cancer: differential expression in triple-negative and non-triple-negative tumors. Breast. 2012;21(2):178-82.

14. Ueng SH, Chen SC, Chang YS, Hsueh S, Lin YC, Chien HP, Lo YF, Shen SC, Hsueh C. Phosphorylated mTOR expression correlates with poor outcome in early-stage triple negative breast carcinomas. Int $\mathrm{J}$ Clin Exp Pathol. 2012;5(8):806-13.

15. Bahrami A, Khazaei M, Shahidsales S, Hassanian SM, Hasanzadeh M, Maftouh M, Ferns GA, Avan A. The Therapeutic Potential of PI3K/Akt/mTOR Inhibitors in Breast Cancer: Rational and Progress. J Cell Biochem. 2018;119(1):213-22.

16. Ge H, Roeder RG. Purification, cloning, and characterization of a human coactivator, PC4, that mediates transcriptional activation of class II genes. Cell. 1994;78(3):513-23.

17. Kretzschmar M, Kaiser K, Lottspeich F, Meisterernst $M$. A novel mediator of class II gene transcription with homology to viral immediate-early transcriptional regulators. Cell. 1994;78(3):525-34.

18. Malik S, Guermah M, Roeder RG. A dynamic model for PC4 coactivator function in RNA polymerase II transcription. Proc Natl Acad Sci U S A. 1998;95(5):2192-7.

19. Wang Z, Roeder RG. DNA topoisomerase I and PC4 can interact with human TFIIIC to promote both accurate termination and transcription reinitiation by RNA polymerase III. Mol Cell. 1998;1(5):749- 
57.

20. Calvo O, Manley JL. The transcriptional coactivator PC4/Sub1 has multiple functions in RNA polymerase II transcription. EMBO J. 2005;24(5):1009-20.

21. Tavenet A, Suleau A, Dubreuil G, Ferrari R, Ducrot C, Michaut M, Aude JC, Dieci G, Lefebvre O, Conesa $\mathrm{C}$, et al. Genome-wide location analysis reveals a role for Sub1 in RNA polymerase III transcription. Proc Natl Acad Sci U S A. 2009;106(34):14265-70.

22. Garavis M, Gonzalez-Polo N, Allepuz-Fuster P, Louro JA, Fernandez-Tornero C, Calvo O. Sub1 contacts the RNA polymerase II stalk to modulate mRNA synthesis. Nucleic Acids Res. 2017;45(5):2458-71.

23. Jo J, Hwang S, Kim HJ, Hong S, Lee JE, Lee SG, Baek A, Han H, Lee Jl, Lee I, et al. An integrated systems biology approach identifies positive cofactor 4 as a factor that increases reprogramming efficiency. Nucleic Acids Res. 2016;44(3):1203-15.

24. Kim JM, Kim K, Schmidt T, Punj V, Tucker H, Rice JC, Ulmer TS, An W. Cooperation between SMYD3 and PC4 drives a distinct transcriptional program in cancer cells. Nucleic Acids Res. 2015;43(18):8868-83.

25. Gao J, Zybailov BL, Byrd AK, Griffin WC, Chib S, Mackintosh SG, Tackett AJ, Raney KD. Yeast transcription co-activator Sub1 and its human homolog PC4 preferentially bind to G-quadruplex DNA. Chem Commun (Camb). 2015;51(33):7242-4.

26. Huang J, Zhao Y, Liu H, Huang D, Cheng X, Zhao W, Taylor IA, Liu J, Peng YL. Substitution of tryptophan 89 with tyrosine switches the DNA binding mode of PC4. Sci Rep. 2015;5:8789.

27. Qian D, Zhang B, Zeng XL, Le Blanc JM, Guo YH, Xue C, Jiang C, Wang HH, Zhao TS, Meng MB, et al. Inhibition of human positive cofactor 4 radiosensitizes human esophageal squmaous cell carcinoma cells by suppressing XLF-mediated nonhomologous end joining. Cell Death Dis. 2014;5:e1461.

28. Das C, Hizume K, Batta K, Kumar BR, Gadad SS, Ganguly S, Lorain S, Verreault A, Sadhale PP, Takeyasu K, et al. Transcriptional coactivator PC4, a chromatin-associated protein, induces chromatin condensation. Mol Cell Biol. 2006;26(22):8303-15.

29. Das C, Gadad SS, Kundu TK. Human positive coactivator 4 controls heterochromatinization and silencing of neural gene expression by interacting with REST/NRSF and CoREST. J Mol Biol. 2010;397(1):1-12.

30. Peng Y, Yang J, Zhang E, Sun H, Wang Q, Wang T, Su Y, Shi C. Human positive coactivator 4 is a potential novel therapeutic target in non-small cell lung cancer. Cancer Gene Ther. 2012;19(10):6906.

31. Chen L, Du C, Wang L, Yang C, Zhang JR, Li N, Li Y, Xie XD, Gao GD. Human positive coactivator 4 (PC4) is involved in the progression and prognosis of astrocytoma. J Neurol Sci. 2014;346(12):293-8.

32. Chakravarthi BV, Goswami MT, Pathi SS, Robinson AD, Cieslik M, Chandrashekar DS, Agarwal S, Siddiqui J, Daignault S, Carskadon SL, et al. MicroRNA-101 regulated transcriptional modulator SUB1 plays a role in prostate cancer. Oncogene. 2016;35(49):6330-40. 
33. Luo P, Jiang Q, Fang Q, Wang Y, Wang Z, Yang J, Tan X, Li W, Shi C. The human positive cofactor 4 promotes androgen-independent prostate cancer development and progression through HIF1alpha/beta-catenin pathway. Am J Cancer Res. 2019;9(4):682-98.

34. Isakoff SJ, Mayer EL, He L, Traina TA, Carey LA, Krag KJ, Rugo HS, Liu MC, Stearns V, Come SE, et al. TBCRC009: A Multicenter Phase II Clinical Trial of Platinum Monotherapy With Biomarker Assessment in Metastatic Triple-Negative Breast Cancer. J Clin Oncol. 2015;33(17):1902-9.

35. Liao F, Chen L, Luo P, Jiang Z, Chen Z, Wang Z, Zhang C, Wang Y, He J, Wang Q, et al. PC4 serves as a negative regulator of skin wound healing in mice. Burns Trauma. 2020;8:tkaa010.

36. Zhang T, Liu X, Chen X, Wang J, Wang Y, Qian D, Pang Q, Wang P. Inhibition of PC4 radiosensitizes non-small cell lung cancer by transcriptionally suppressing XLF. Cancer Med. 2018;7(4):1326-37.

\section{Figures}


a

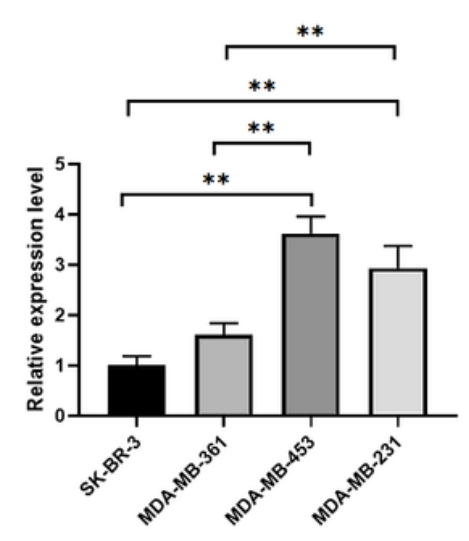

C

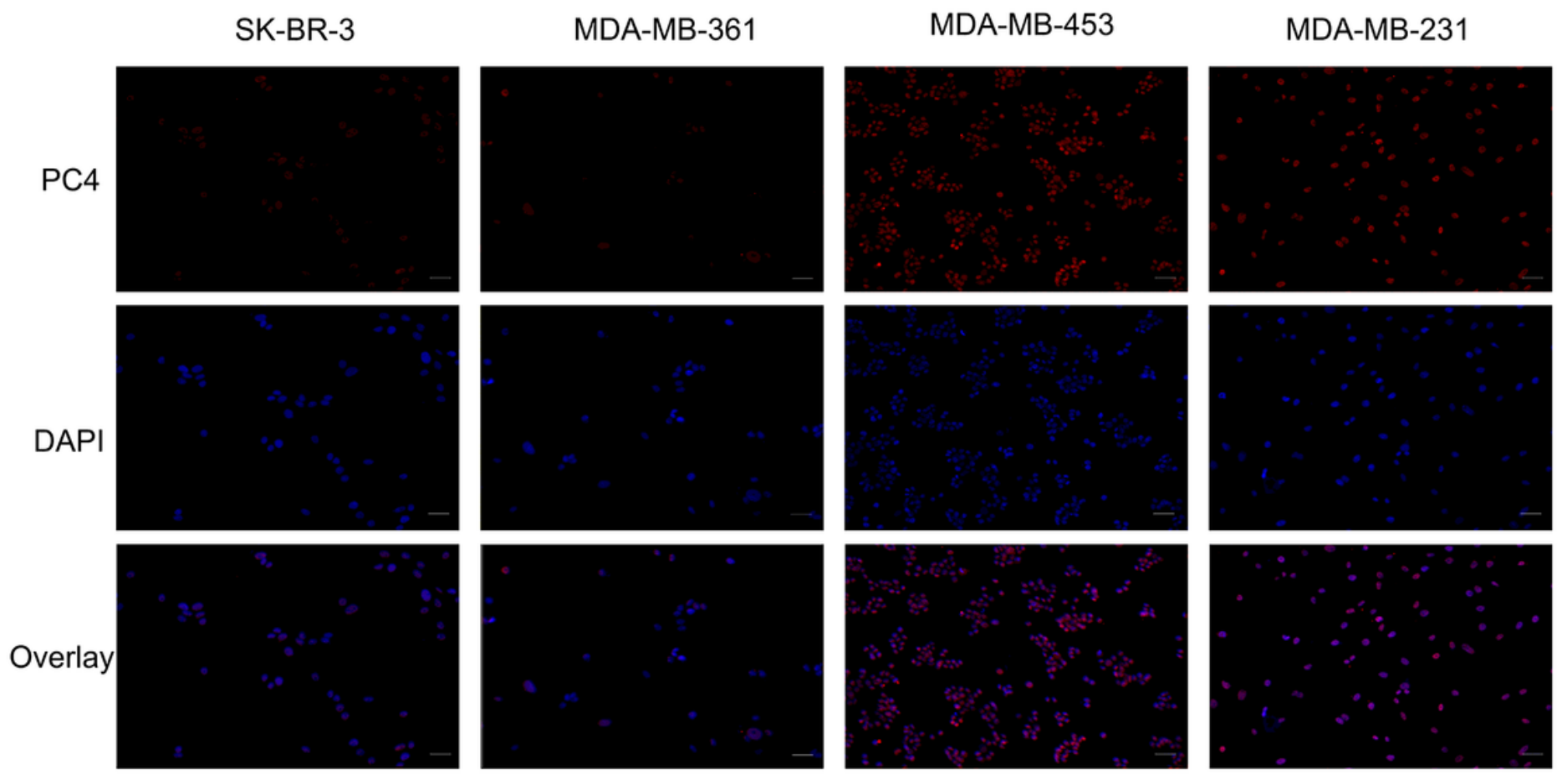

b

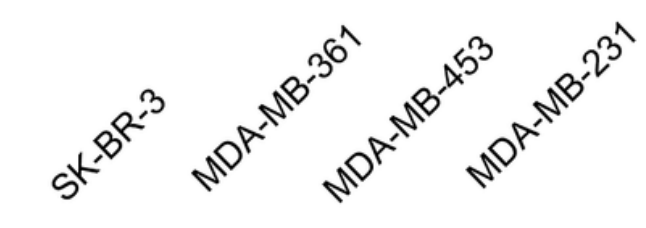

PC4

$\beta$-actin
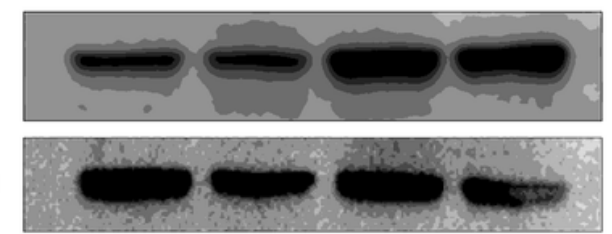

MDA-MB-453

MDA-MB-231

\section{Figure 1}

PC4 is significantly upregulated in triple negative breast cancer. a. The mRNA level of PC4 in non-TNBC cell lines (SK-BR3, MDA-MB-361) and TNBC cell lines (MDA-MB-231, MDA-MB-453). $n=3 \mathrm{~b}$. The protein level of PC4 in non-TNBC cell lines (SK-BR3, MDA-MB-361) and TNBC cell lines. c. Immunofluorescent staining for PC4 expression in non-TNBC cell lines (SK-BR3, MDA-MB-361) and TNBC cell lines (MDA-MB231, MDA-MB-453). Scale bar represents $50 \mu \mathrm{m}$. one-way ANOVA 
a

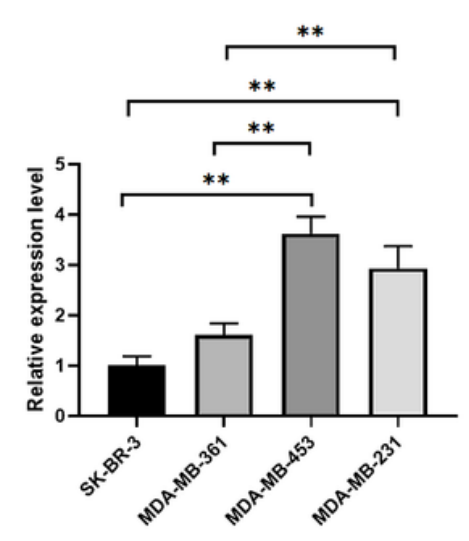

C

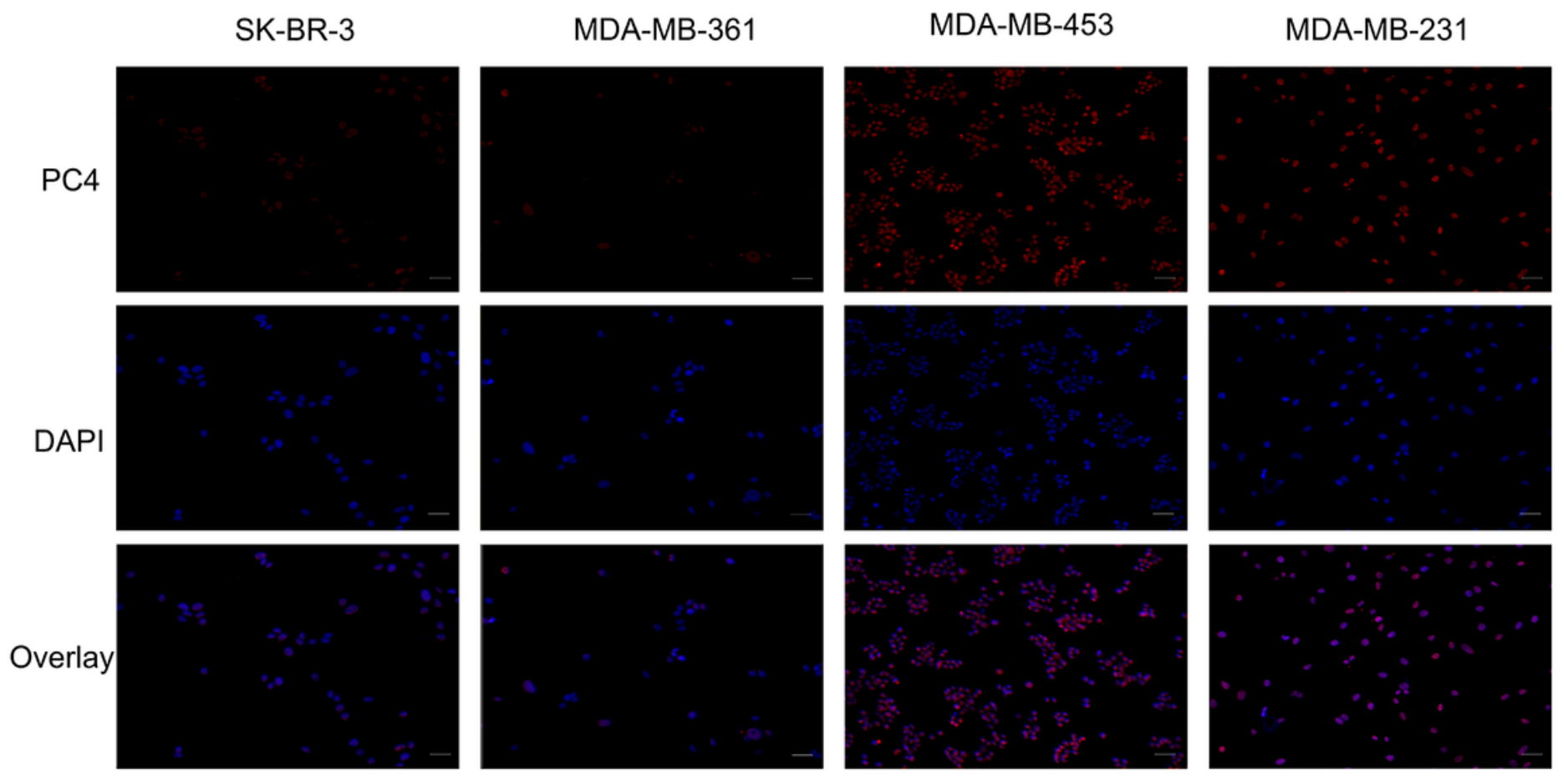

b

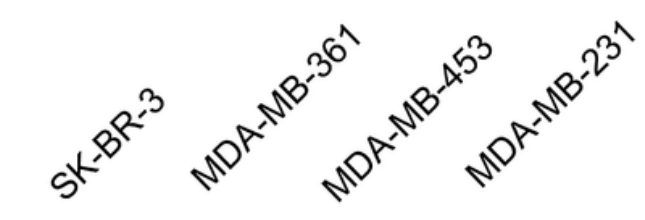

PC4

$\beta$-actin
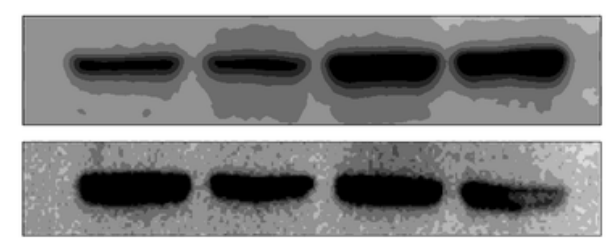

MDA-MB-453

MDA-MB-231

\section{Figure 1}

PC4 is significantly upregulated in triple negative breast cancer. a. The mRNA level of PC4 in non-TNBC cell lines (SK-BR3, MDA-MB-361) and TNBC cell lines (MDA-MB-231, MDA-MB-453). $n=3 \mathrm{~b}$. The protein level of PC4 in non-TNBC cell lines (SK-BR3, MDA-MB-361) and TNBC cell lines. c. Immunofluorescent staining for PC4 expression in non-TNBC cell lines (SK-BR3, MDA-MB-361) and TNBC cell lines (MDA-MB231, MDA-MB-453). Scale bar represents $50 \mu \mathrm{m}$. one-way ANOVA 
a

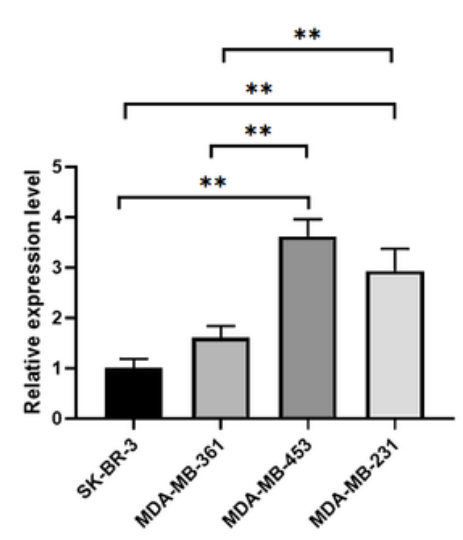

C

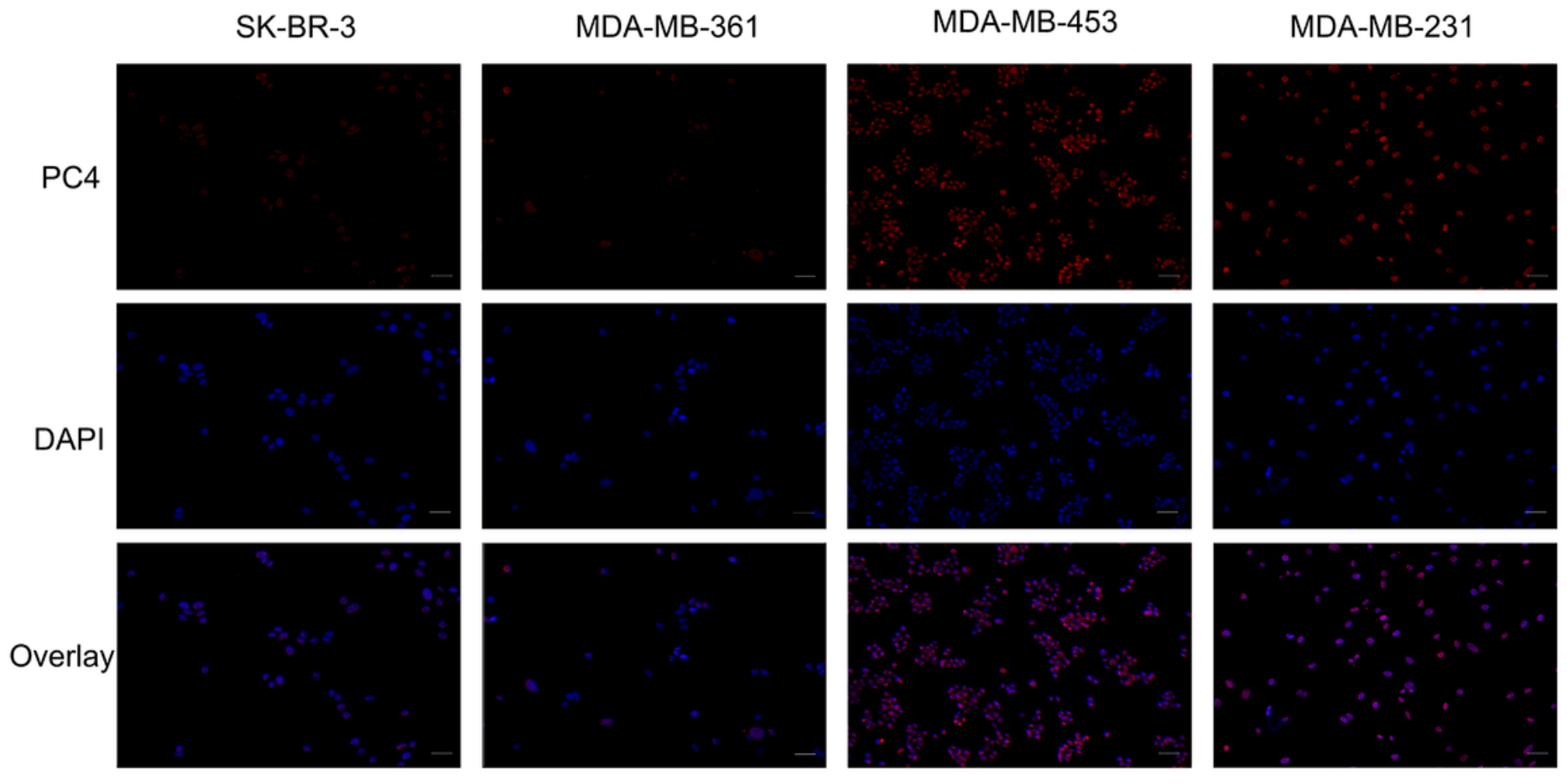

b

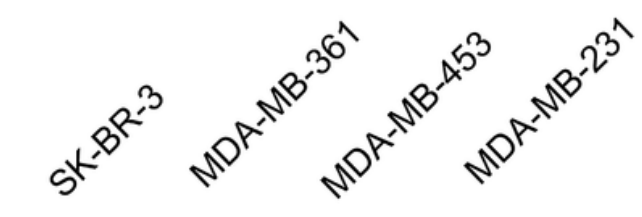

PC4

$\beta$-actin
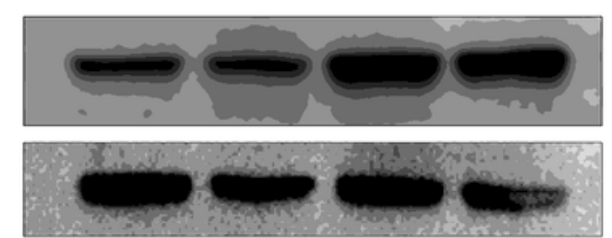
a
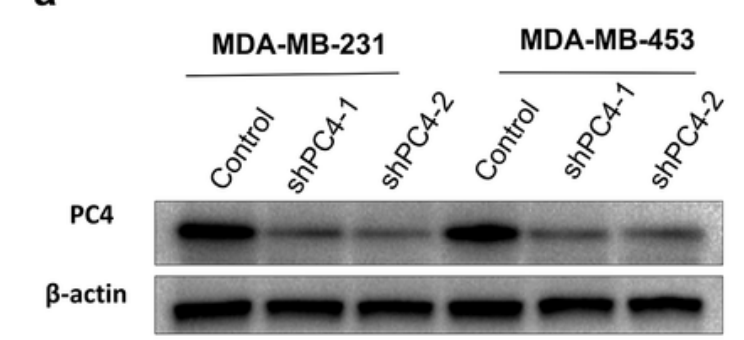

b
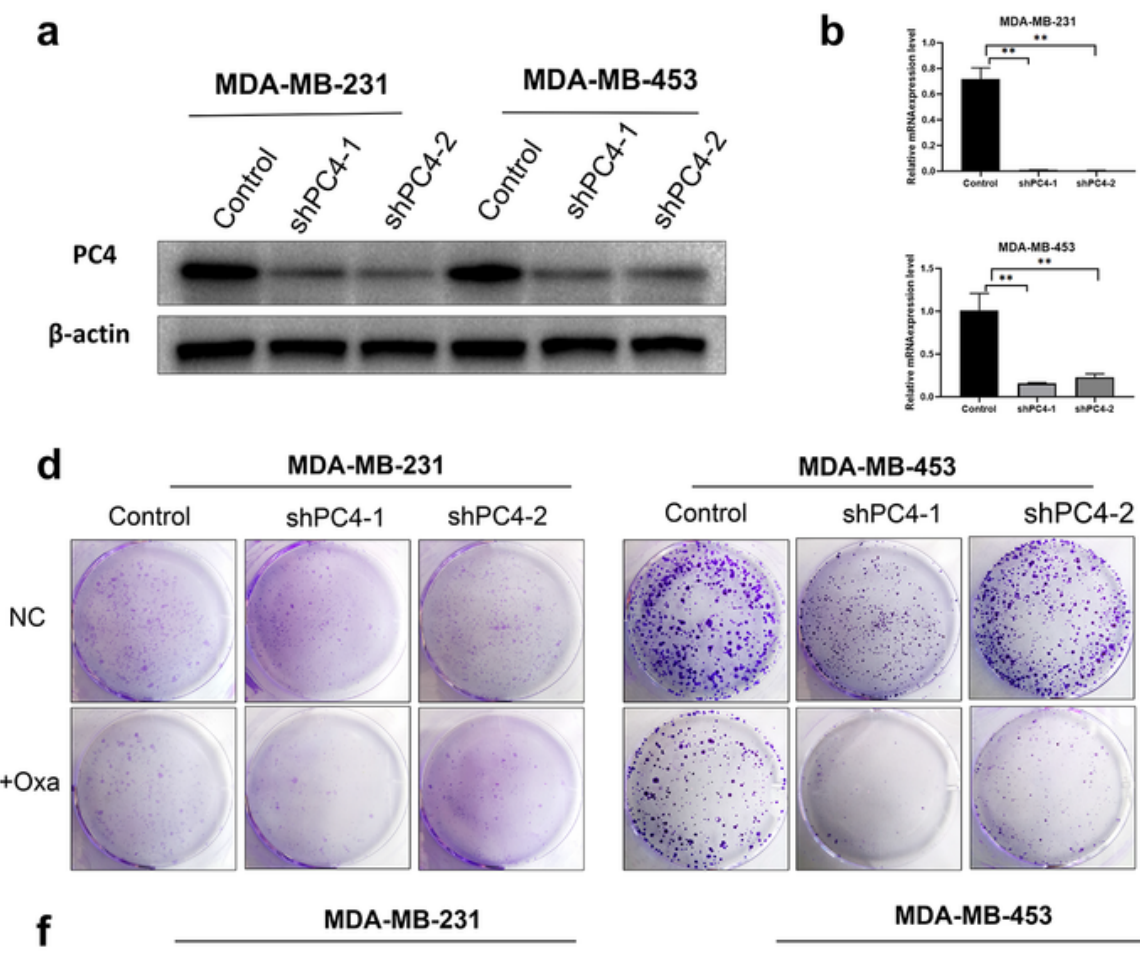

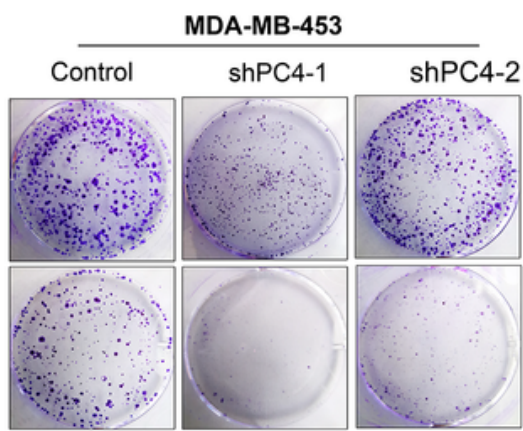

MDA-MB-453
C
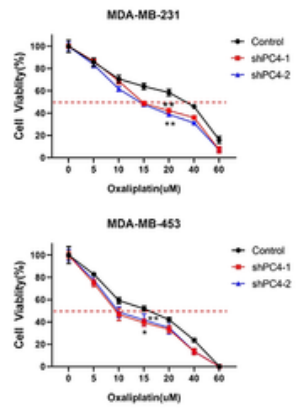

e
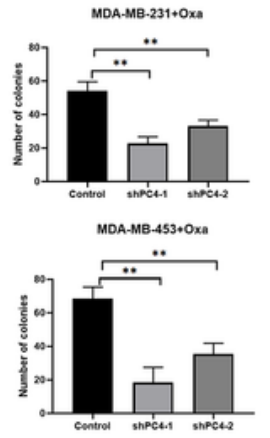

g

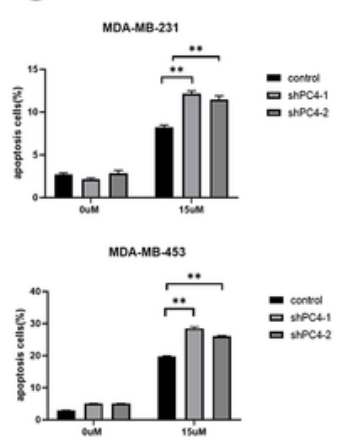

wis

APC-Annexin V

h

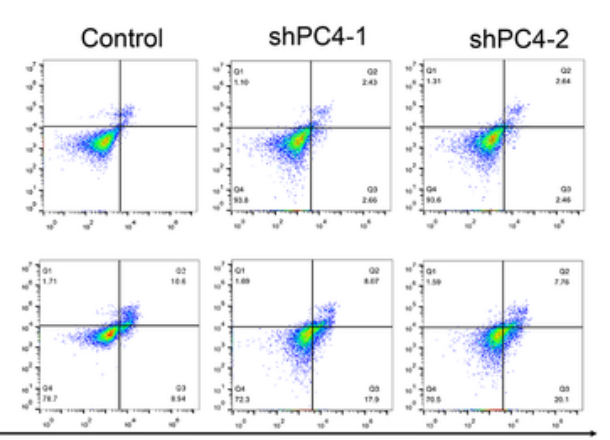

PI +Oxa
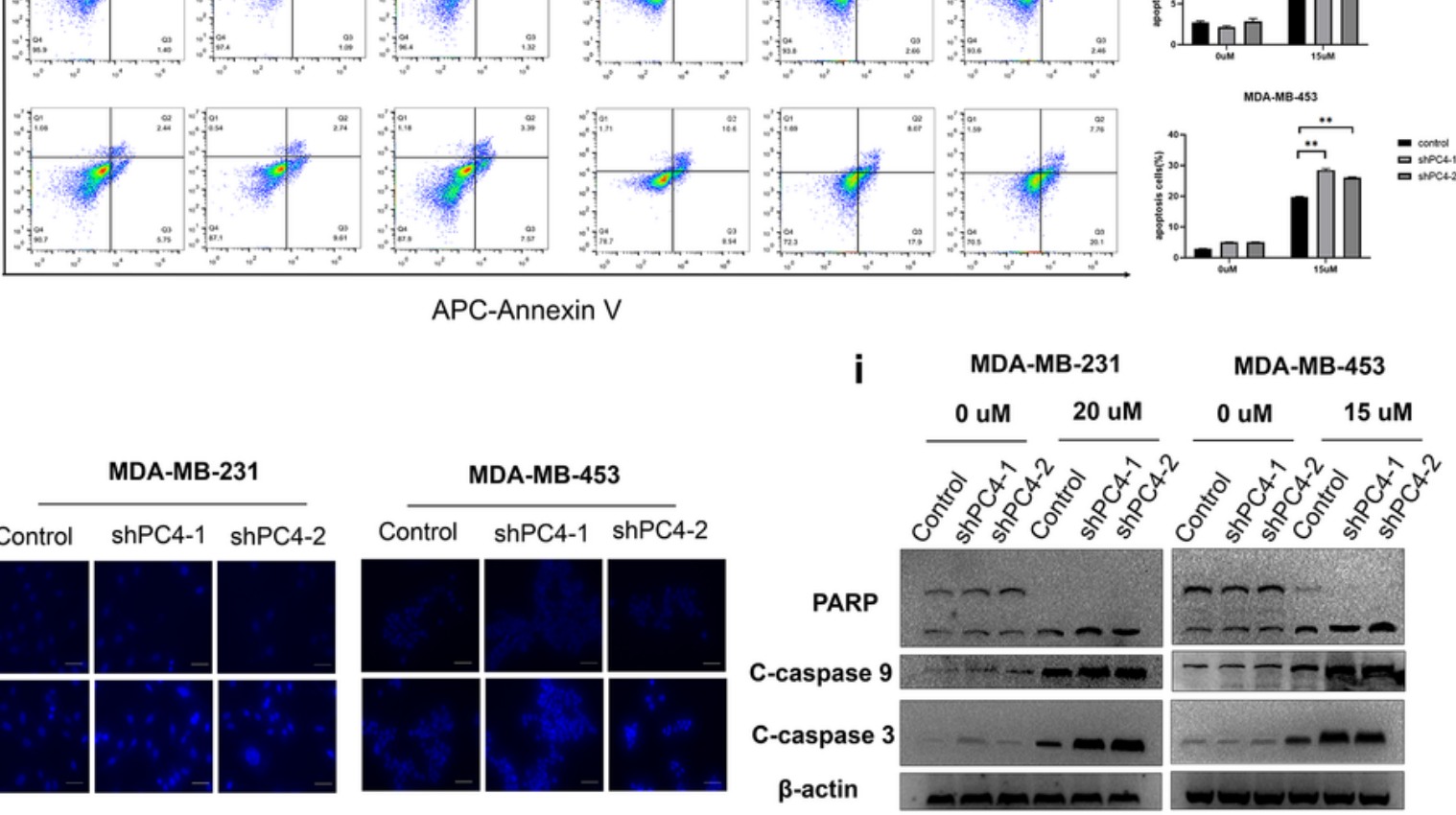

Figure 2

Knockdown of PC4 significantly enhance the chemosensitivity of TNBC cells to Oxa in vitro PC4 knockdown cell lines were established by two shRNAs, and the efficiency was examined by western blot (a) and qPCR (b). c. Cell viability was detected by CCK-8 assay $48 \mathrm{~h}$ after indicated concentration of Oxa or vehicle treatment. $n=5$. $d$. Colony formation was stained by crystal violet two weeks after Oxa treatment. e. Statistical analysis of colony formation. $n=3$. f. Apoptotic cells (annexin V positive) was 
detected by flow cytometry 48 hours after $0 x a$ or vehicle treatment. g. Statistical analysis of apoptotic cells, $n=3$. h. Immunofluorescence staining of Hoechst 33342, scale bar, $25 \mu \mathrm{m}$. i. Western Blotting analysis of apoptosis-related protein 48 hours after Oxa or vehicle treatment, $\beta$-actin was used as the sample loading control. one-way ANOVA, ${ }^{*} \mathrm{P}<0.05,{ }^{*} \mathrm{P}<0.01$.

a

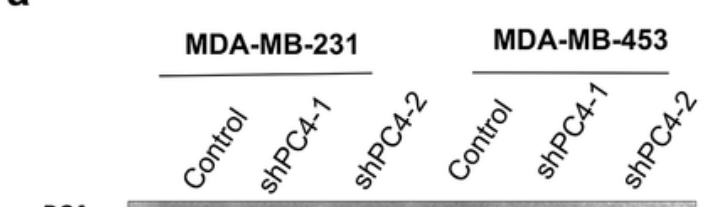

PC4

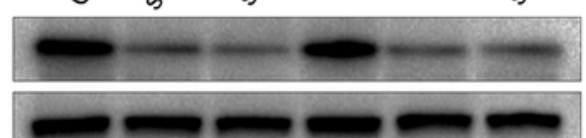

$\beta$-actin
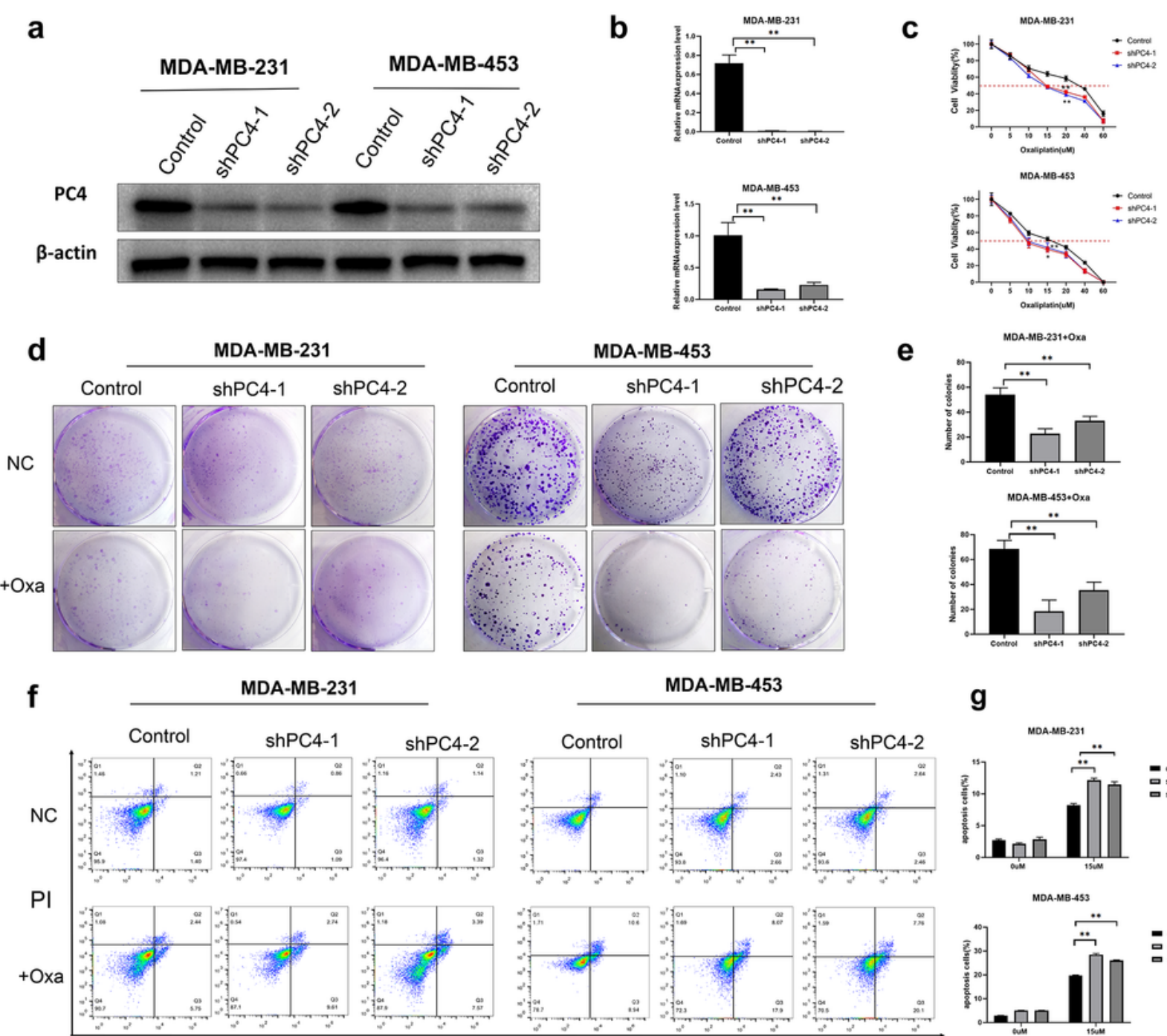

e
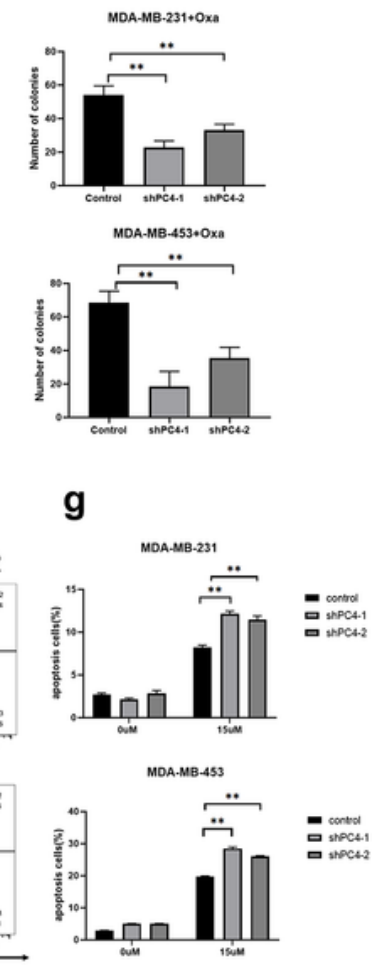

APC-Annexin V

h
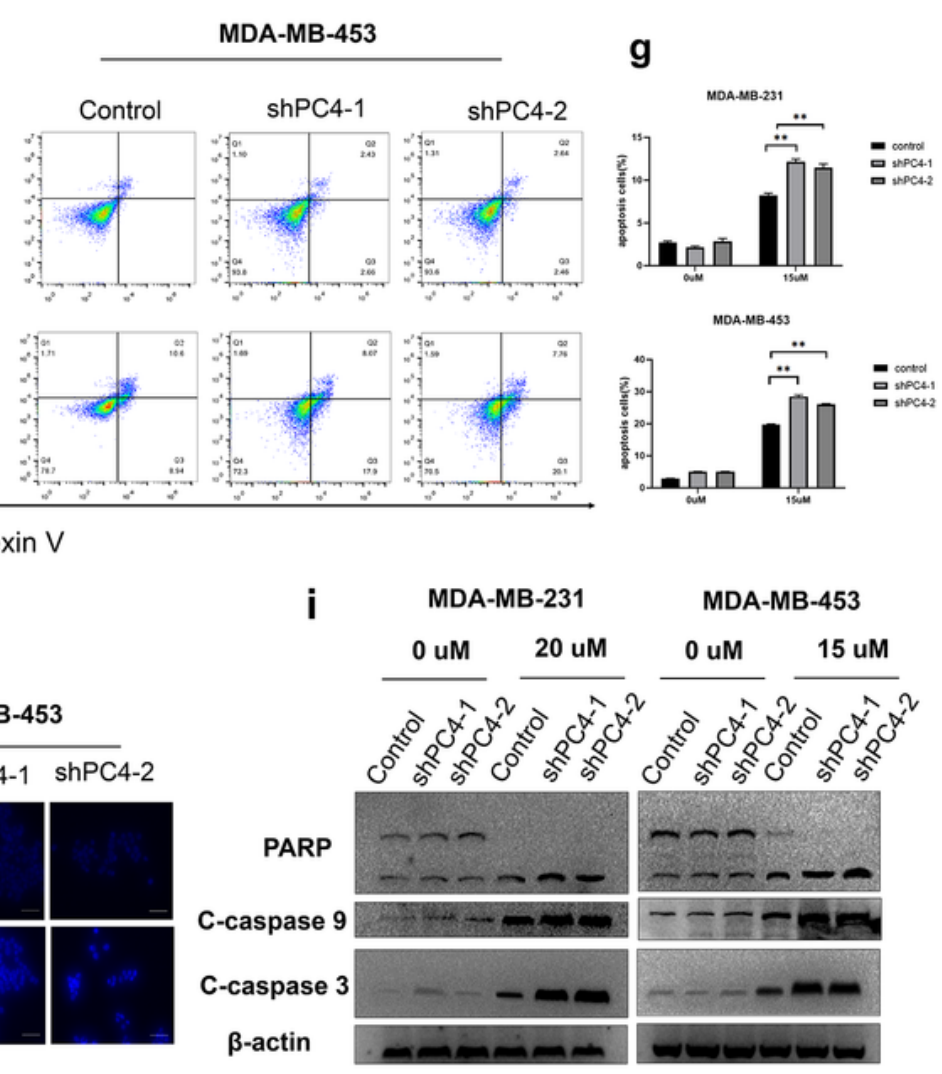

MDA-MB-453
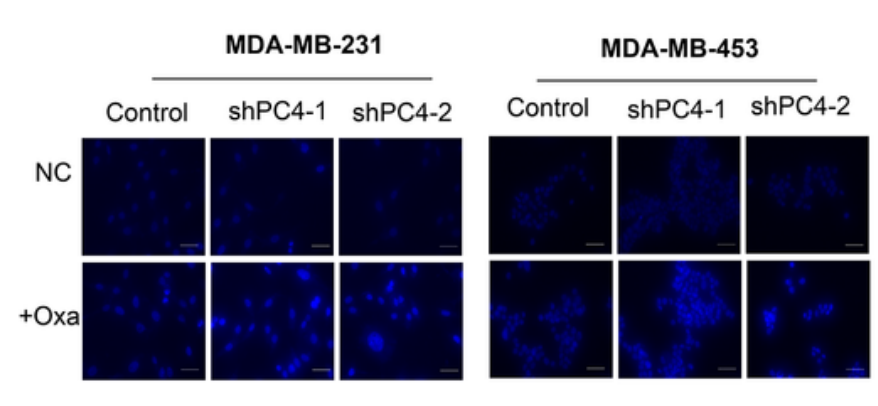

MDA-MB-453

$\beta$-actin

Figure 2 
Knockdown of PC4 significantly enhance the chemosensitivity of TNBC cells to Oxa in vitro PC4 knockdown cell lines were established by two shRNAs, and the efficiency was examined by western blot (a) and qPCR (b). c. Cell viability was detected by CCK-8 assay $48 \mathrm{~h}$ after indicated concentration of Oxa or vehicle treatment. $n=5$. $d$. Colony formation was stained by crystal violet two weeks after $0 x a$ treatment. e. Statistical analysis of colony formation. $n=3$. f. Apoptotic cells (annexin V positive) was detected by flow cytometry 48 hours after $0 x a$ or vehicle treatment. g. Statistical analysis of apoptotic cells, $n=3$. h. Immunofluorescence staining of Hoechst 33342, scale bar, $25 \mu \mathrm{m}$. i. Western Blotting analysis of apoptosis-related protein 48 hours after Oxa or vehicle treatment, $\beta$-actin was used as the sample loading control. one-way ANOVA, ${ }^{*}<<0.05,{ }^{*} \mathrm{P}<0.01$. 
a
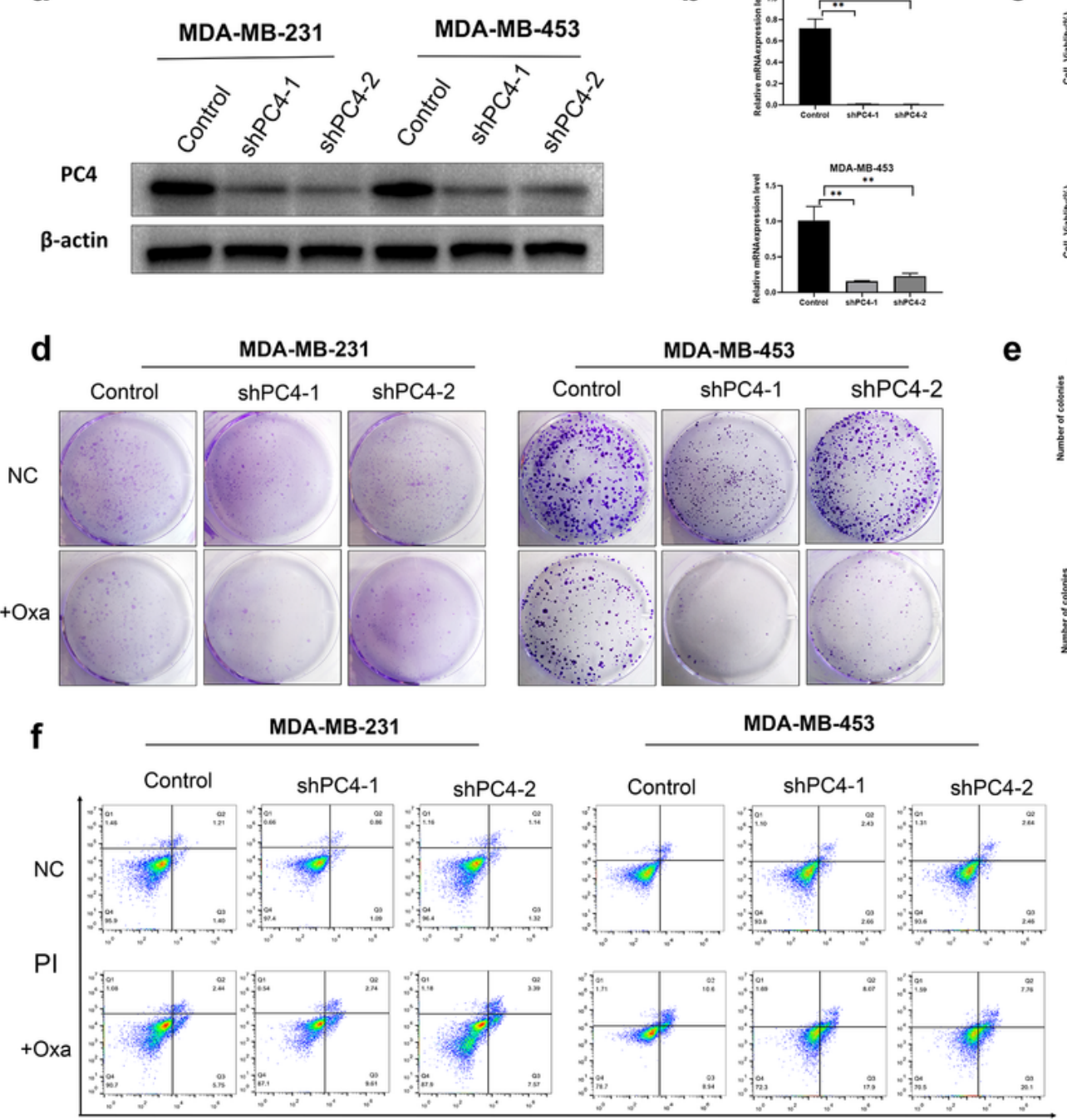

APC-Annexin V

h

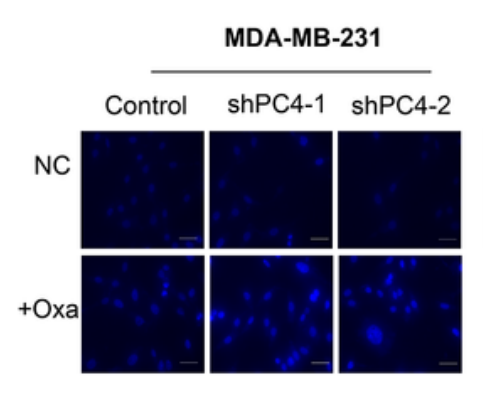

MDA-MB-453

b
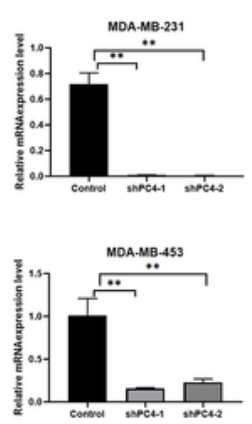

e
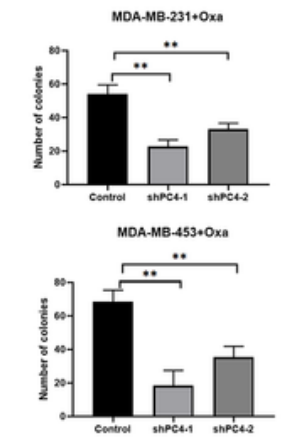

g

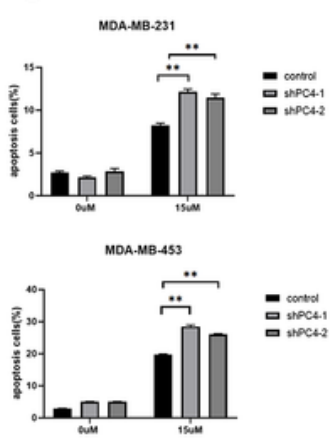

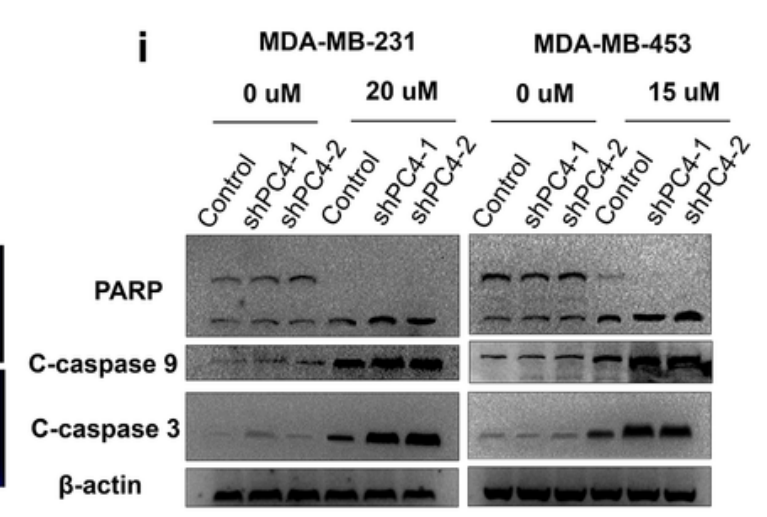

\section{Figure 2}

Knockdown of PC4 significantly enhance the chemosensitivity of TNBC cells to Oxa in vitro PC4 knockdown cell lines were established by two shRNAs, and the efficiency was examined by western blot (a) and qPCR (b). c. Cell viability was detected by CCK-8 assay $48 \mathrm{~h}$ after indicated concentration of Oxa or vehicle treatment. $n=5$. $d$. Colony formation was stained by crystal violet two weeks after Oxa treatment. e. Statistical analysis of colony formation. $n=3$. f. Apoptotic cells (annexin V positive) was 
detected by flow cytometry 48 hours after Oxa or vehicle treatment. g. Statistical analysis of apoptotic cells, $n=3$. h. Immunofluorescence staining of Hoechst 33342, scale bar, $25 \mu \mathrm{m}$. i. Western Blotting analysis of apoptosis-related protein 48 hours after Oxa or vehicle treatment, $\beta$-actin was used as the sample loading control. one-way ANOVA, ${ }^{*} \mathrm{P}<0.05,{ }^{* *} \mathrm{P}<0.01$.

a

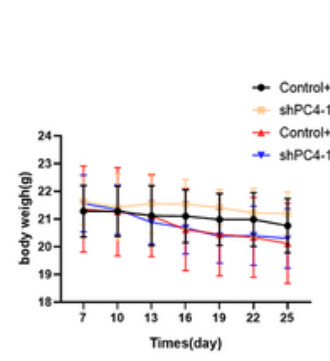

e

Control

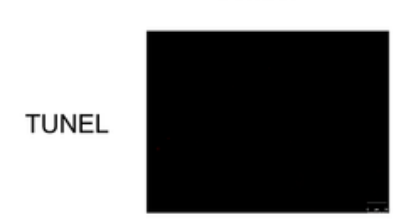

DAPI

Overlay
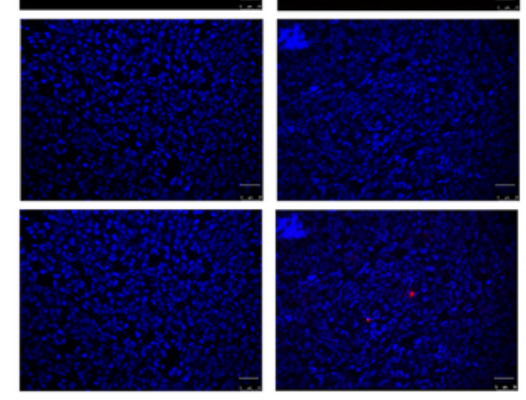

g
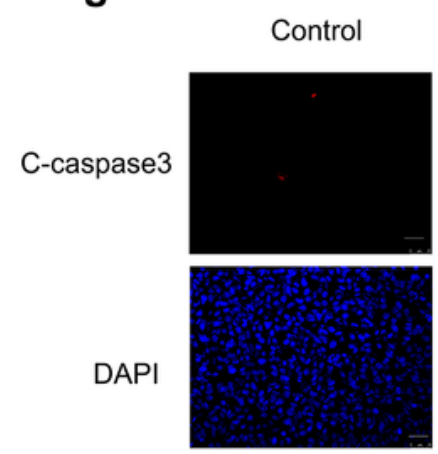

Overlay

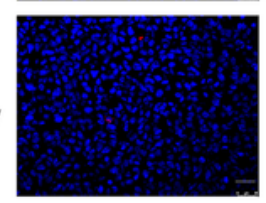

b

shPC4-1
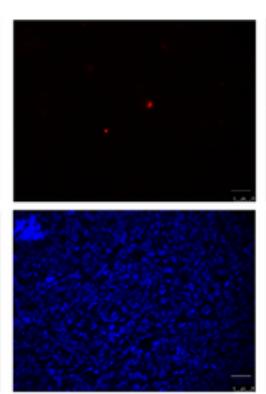

shPC4-1
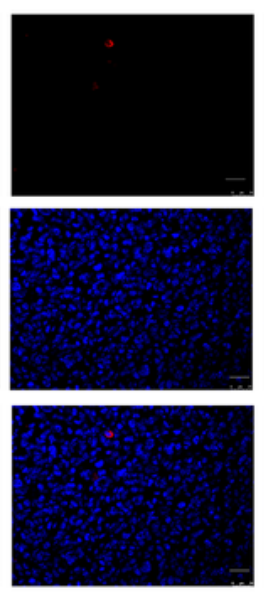
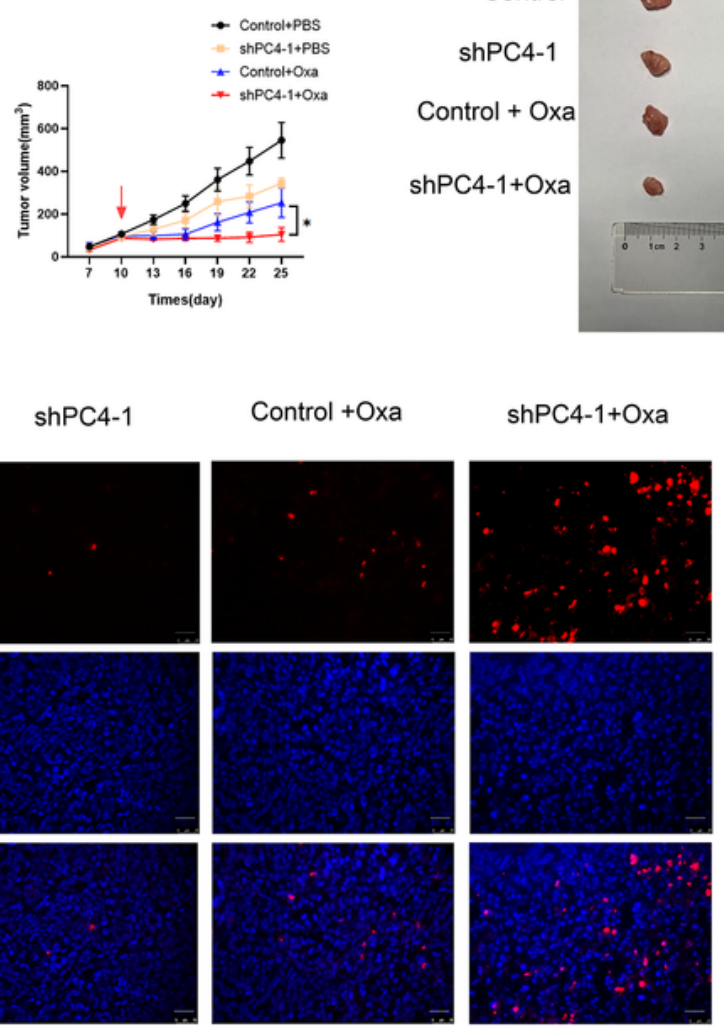

$\mathbf{h}$
Control + Oxa
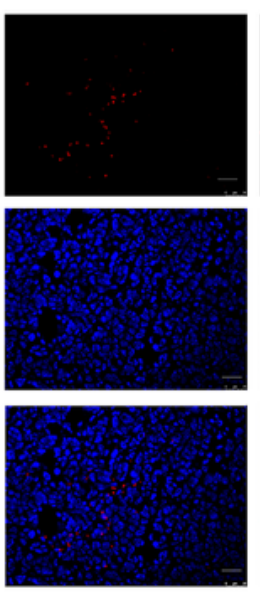

shPC4-1+Oxa
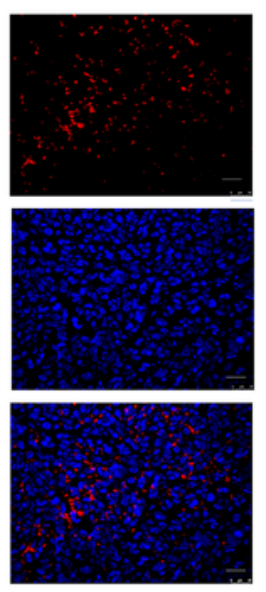

d

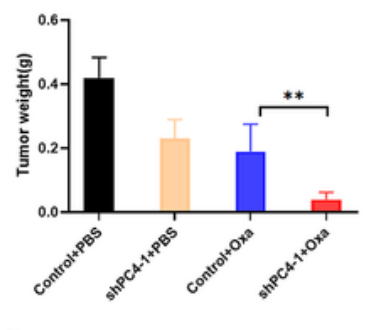

f
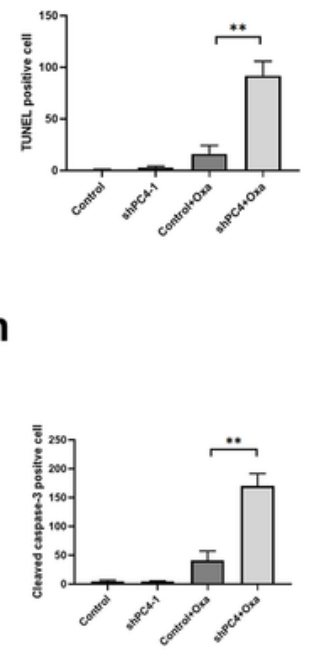

Figure 3 
Knockdown of PC4 sensitize MDA-MB-231 cells to Oxa in vivo The PC4-knockdown MDA-MB-231 cells or control cells were inoculated into athymic female nude mice. a. The body weight of the mice was measured every 3 days. b. Tumor growth curves of the xenograft tumors, the tumor size (volume = length $x$ width2/2) was measured every 3 days, $n=5$. The dissected xenografts were photographed (c) and weighed (d) at the endpoint. $n=5$ e and $f$ Evaluation of apoptosis index by TUNEL staining in the paraffin sections of the tumors. Scale bar, $25 \mu \mathrm{m}, \mathrm{n}=3$. $\mathrm{g}$ and $\mathrm{h}$ Immunofluorescence staining of cleaved Caspase 3 (C-caspase 3 ) in the paraffin sections of the tumors. Scale bar, $25 \mu \mathrm{m}, \mathrm{n}=3$. one-way ANOVA, all data indicate the mean $\pm S D$. ${ }^{*} P<0.05, * * P<0.01$. 
a

b

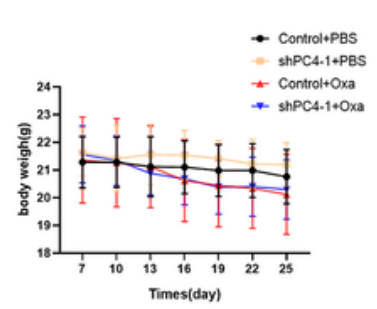

e
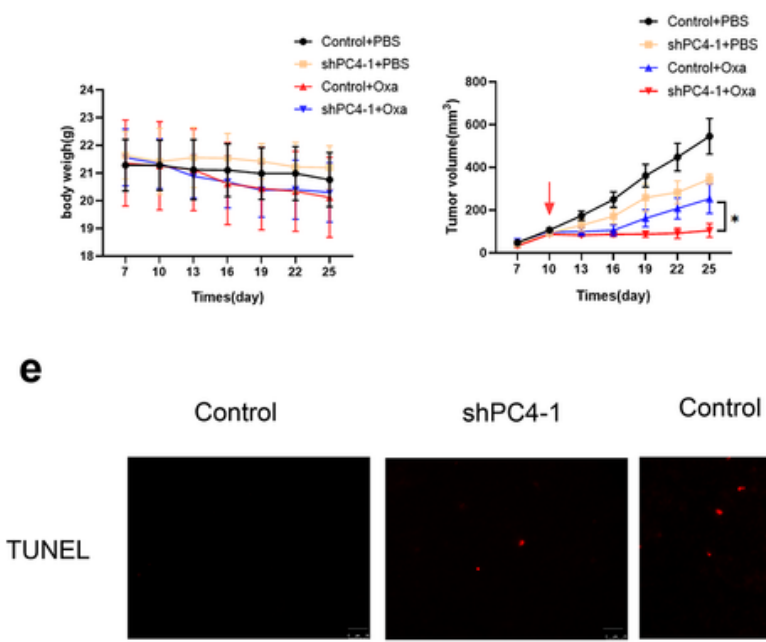

DAPI

g

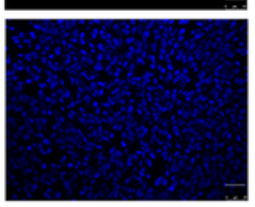

Overlay
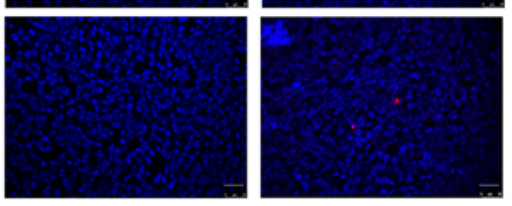

shPC4-1
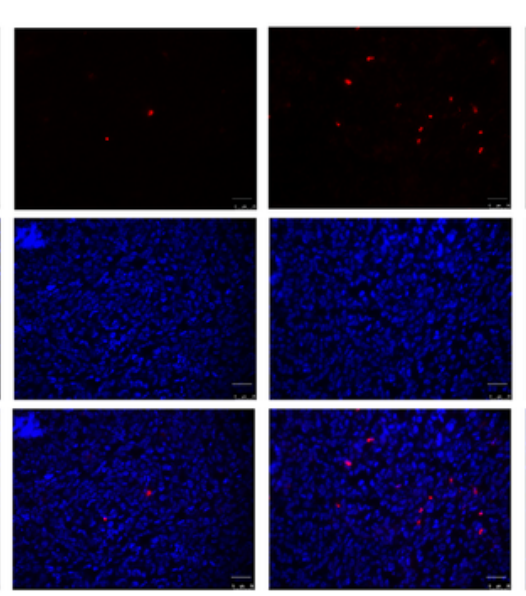

Control +Oxa

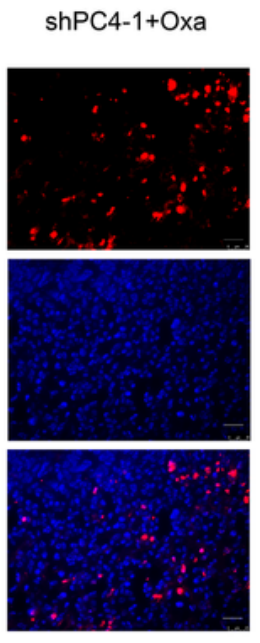

d

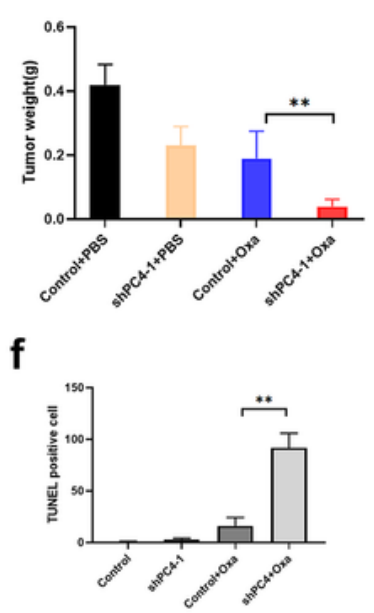

h

Control + Oxa
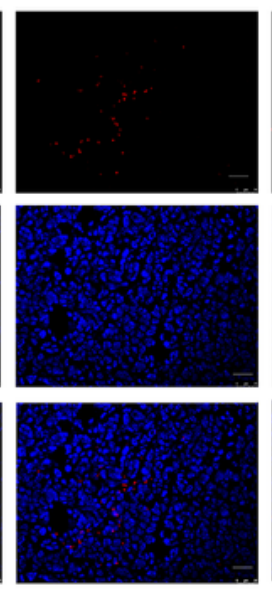

shPC4-1
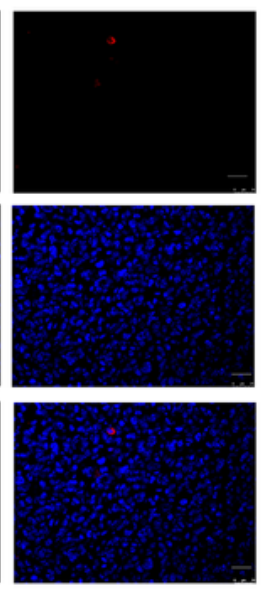

shPC4-1+Oxa
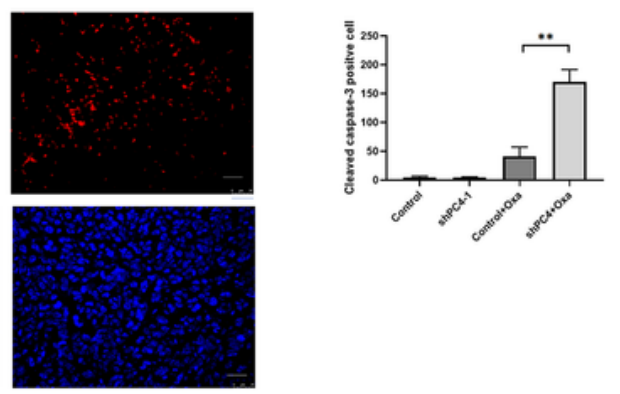

Overlay

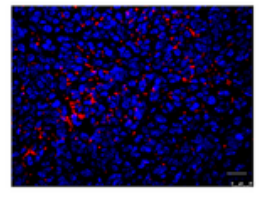

\section{Figure 3}

Knockdown of PC4 sensitize MDA-MB-231 cells to Oxa in vivo The PC4-knockdown MDA-MB-231 cells or control cells were inoculated into athymic female nude mice. a. The body weight of the mice was measured every 3 days. b. Tumor growth curves of the xenograft tumors, the tumor size (volume = length $x$ width2/2) was measured every 3 days, $n=5$. The dissected xenografts were photographed (c) and weighed $(d)$ at the endpoint. $n=5$ e and $f$ Evaluation of apoptosis index by TUNEL staining in the paraffin 
sections of the tumors. Scale bar, $25 \mu \mathrm{m}, \mathrm{n}=3 \mathrm{~g}$ and $\mathrm{h}$ Immunofluorescence staining of cleaved Caspase 3 (C-caspase 3 ) in the paraffin sections of the tumors. Scale bar, $25 \mu \mathrm{m}, \mathrm{n}=3$. one-way ANOVA, all data indicate the mean $\pm S D$. ${ }^{*} P<0.05, * * P<0.01$.

a

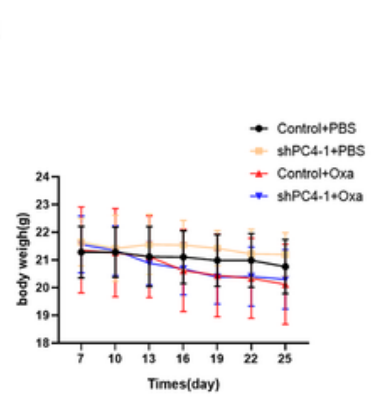

e

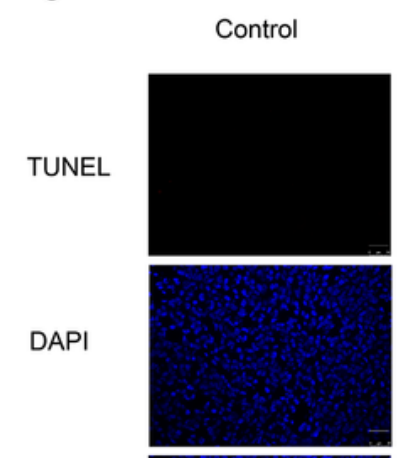

Overlay
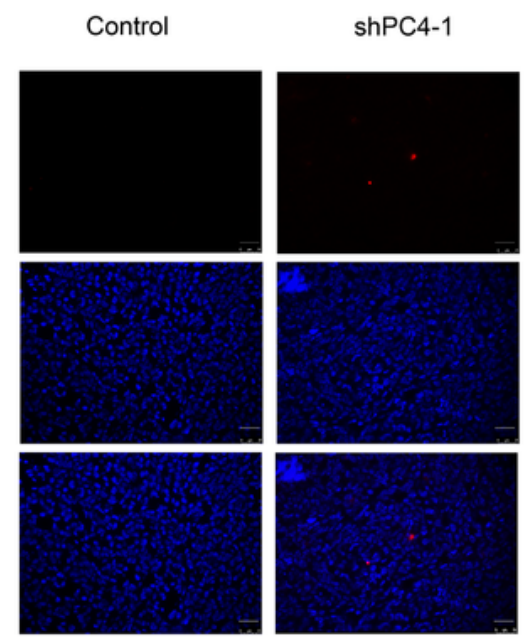

g
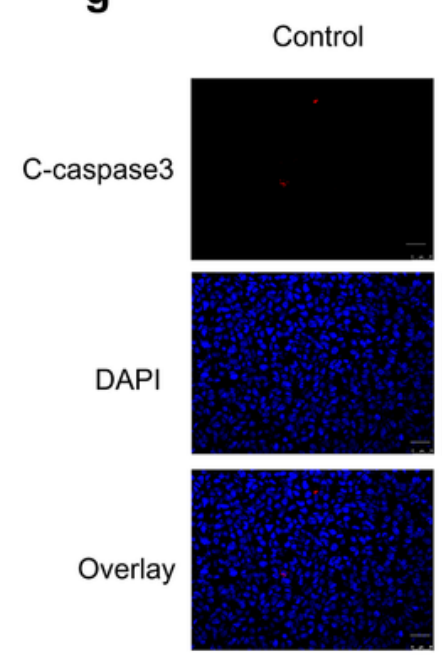

b

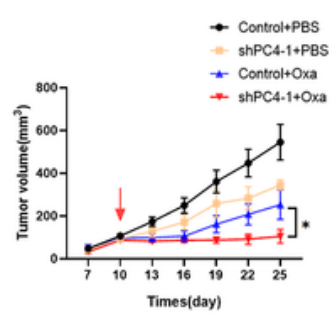

Control +Oxa
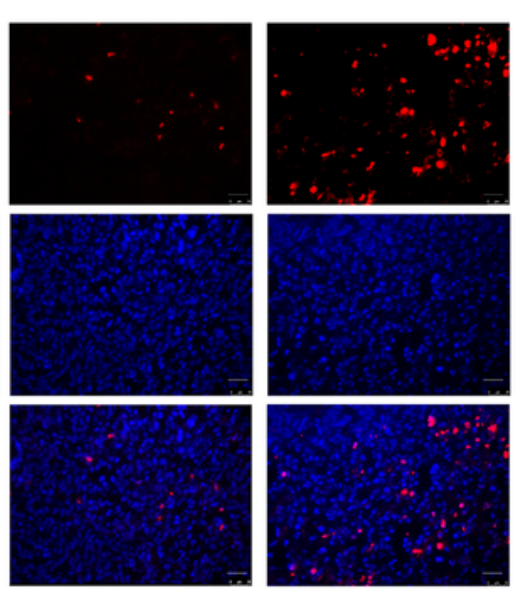

Control + Oxa
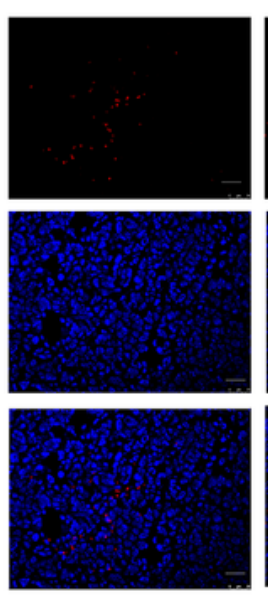

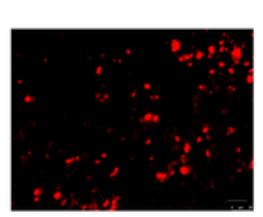

shPC4-1+Oxa
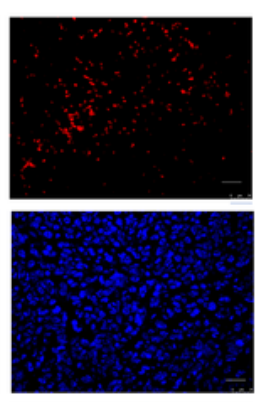

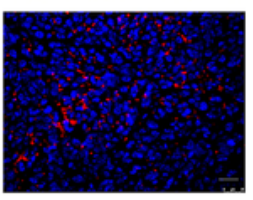

h
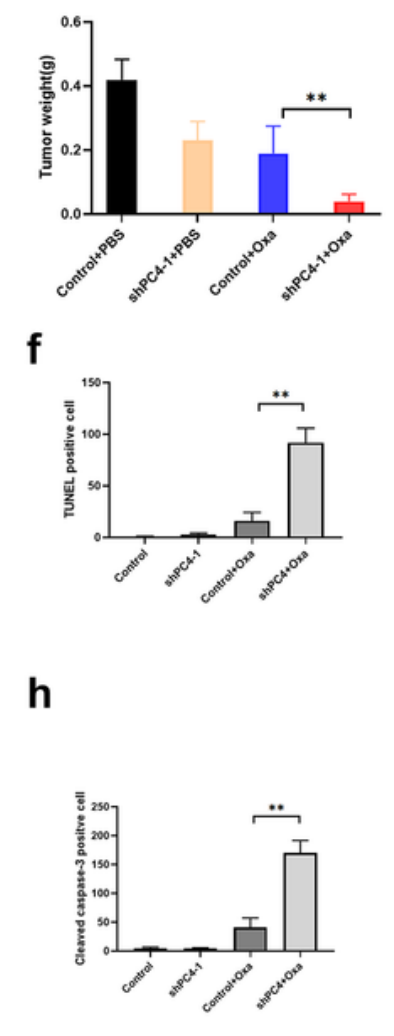

d

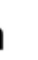

\section{Figure 3}

Knockdown of PC4 sensitize MDA-MB-231 cells to Oxa in vivo The PC4-knockdown MDA-MB-231 cells or control cells were inoculated into athymic female nude mice. a. The body weight of the mice was 
measured every 3 days. b. Tumor growth curves of the xenograft tumors, the tumor size (volume = length $x$ width2/2) was measured every 3 days, $n=5$. The dissected xenografts were photographed (c) and weighed $(d)$ at the endpoint. $n=5$ e and $f$ Evaluation of apoptosis index by TUNEL staining in the paraffin sections of the tumors. Scale bar, $25 \mu \mathrm{m}, \mathrm{n}=3 \mathrm{~g}$ and $\mathrm{h}$ Immunofluorescence staining of cleaved Caspase 3 (C-caspase 3 ) in the paraffin sections of the tumors. Scale bar, $25 \mu \mathrm{m}, \mathrm{n}=3$. one-way ANOVA, all data indicate the mean $\pm S D$. ${ }^{*} P<0.05, * * P<0.01$.

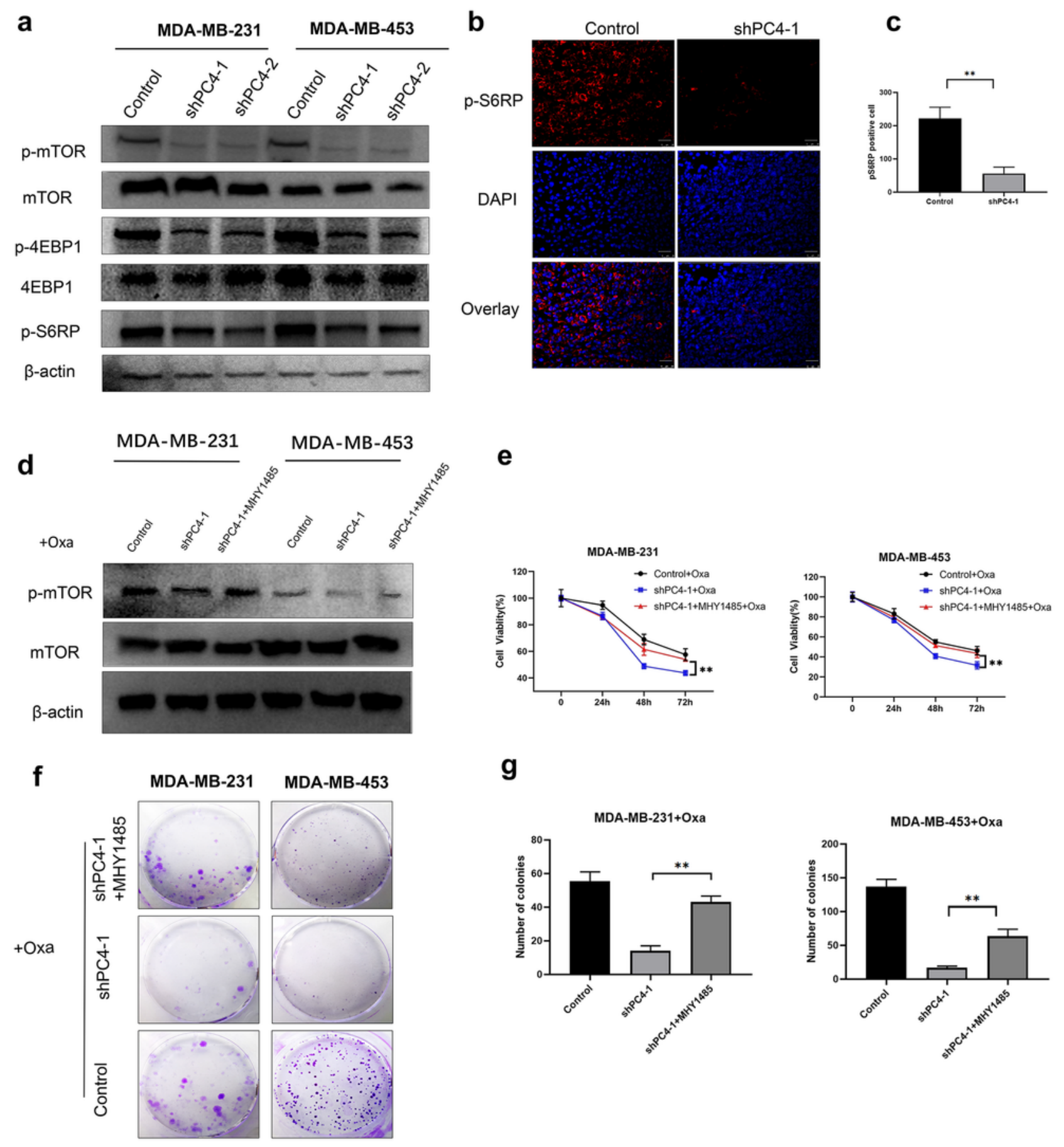

Figure 4 
PC4 knockdown enhances the Oxa-induced growth inhibition in TNBC cells by downregulating mTOR pathway. a. Western Blot analysis of the mTOR pathway (p-mTOR, mTOR, p-4EBP1, t-4EBP1, p-S6RP). $\beta$ actin, sample loading control. b. Immunofluorescence staining of $p$ - S6RP in paraffin sections of xenografts. c. Statistical analysis of p-S6BP immunofluorescence staining using ImageJ analyzing software. $n=3 \mathrm{~d}$. Western Blot analysis of the mTOR and p-mTOR after combination therapy of MHY1485 and Oxa in PC4 knockdown cells, $\beta$-actin, the sample loading control. e. Cell viability was detected by CCK-8 assay 48 hours after combination therapy of MHY 1485 and $0 x a, n=5$. f. Colony formation assay after combination therapy of MHY1485 and Oxa. g. Statistical analysis of the colony formation assay, $\mathrm{n}=3$. cells were pretreated by MHY 1485 for 24 hours, then incubated with indicated concentration of Oxa for 48 hours. MHY1485, a mTOR activator. The Student's t-test for (c), one-way ANOVA for (e and g), all data indicate the mean $\pm S D, * p<0.05,{ }^{*} p p<0.01$. 


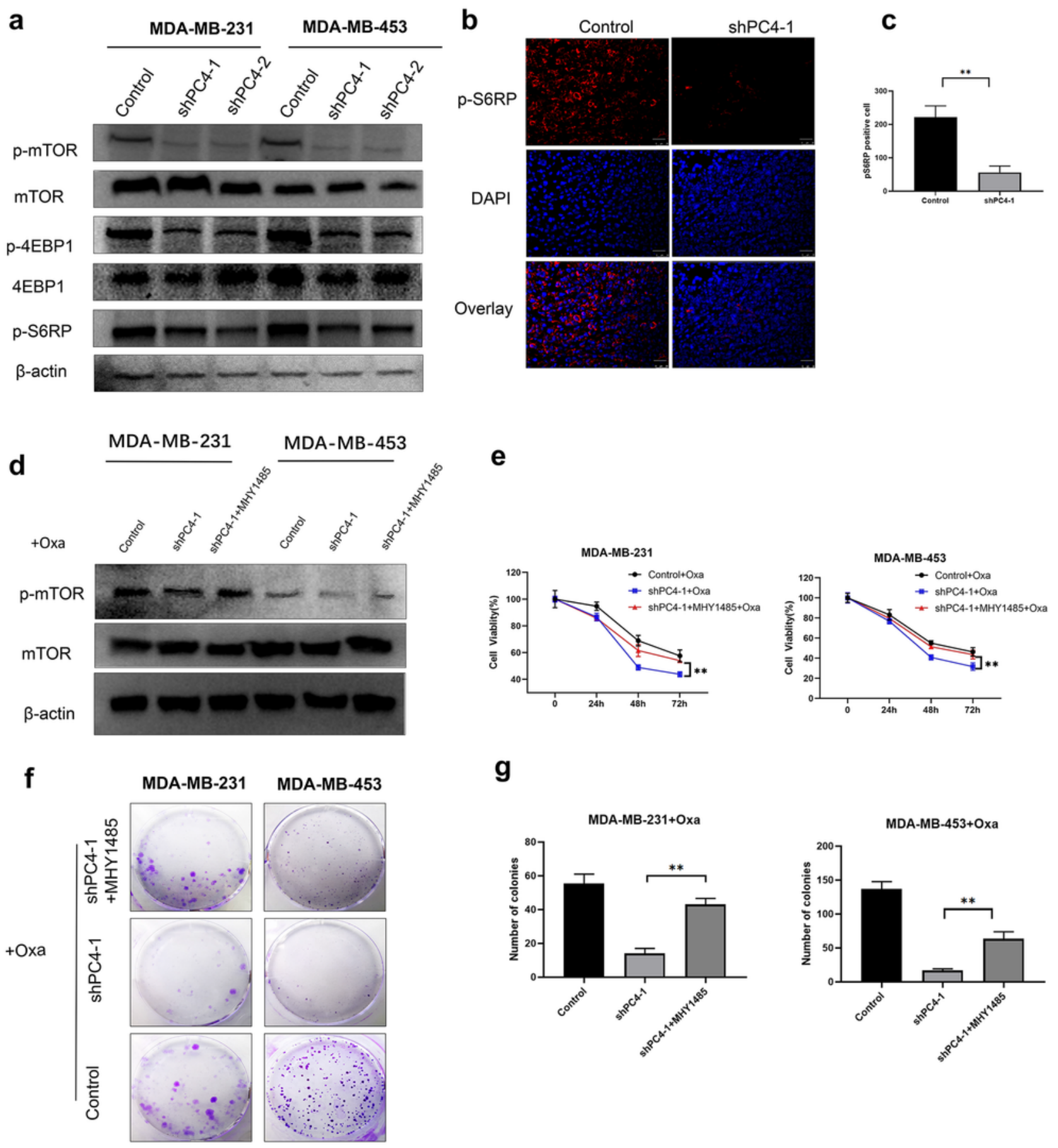

\section{Figure 4}

PC4 knockdown enhances the Oxa-induced growth inhibition in TNBC cells by downregulating mTOR pathway. a. Western Blot analysis of the mTOR pathway (p-mTOR, mTOR, p-4EBP1, t-4EBP1, p-S6RP). $\beta$ actin, sample loading control. b. Immunofluorescence staining of p-S6RP in paraffin sections of xenografts. c. Statistical analysis of p-S6BP immunofluorescence staining using ImageJ analyzing software. $n=3 \mathrm{~d}$. Western Blot analysis of the mTOR and p-mTOR after combination therapy of MHY1485 
and Oxa in PC4 knockdown cells, $\beta$-actin, the sample loading control. e. Cell viability was detected by CCK-8 assay 48 hours after combination therapy of MHY1485 and 0xa, $n=5$. f. Colony formation assay after combination therapy of MHY1485 and Oxa. g. Statistical analysis of the colony formation assay, $\mathrm{n}=3$. cells were pretreated by MHY1485 for 24 hours, then incubated with indicated concentration of Oxa for 48 hours. MHY1485, a mTOR activator. The Student's t-test for (c), one-way ANOVA for (e and g), all data indicate the mean $\pm S D,{ }^{*}<<0.05,{ }^{*} \mathrm{p}<0.01$.

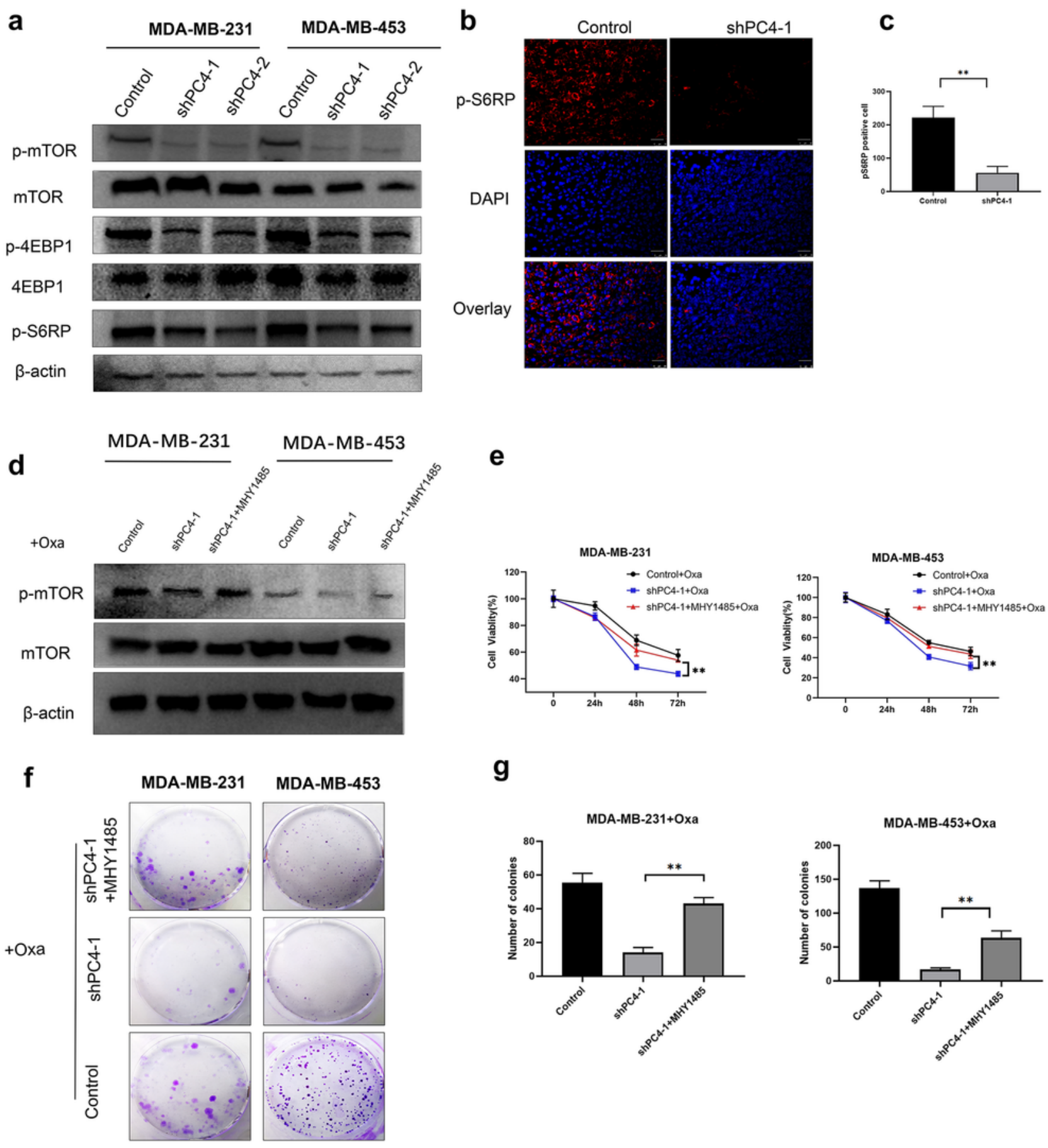

Figure 4 
PC4 knockdown enhances the Oxa-induced growth inhibition in TNBC cells by downregulating mTOR pathway. a. Western Blot analysis of the mTOR pathway (p-mTOR, mTOR, p-4EBP1, t-4EBP1, p-S6RP). $\beta$ actin, sample loading control. b. Immunofluorescence staining of $p$ - S6RP in paraffin sections of xenografts. c. Statistical analysis of p-S6BP immunofluorescence staining using ImageJ analyzing software. $n=3 \mathrm{~d}$. Western Blot analysis of the mTOR and p-mTOR after combination therapy of MHY1485 and Oxa in PC4 knockdown cells, $\beta$-actin, the sample loading control. e. Cell viability was detected by CCK-8 assay 48 hours after combination therapy of MHY 1485 and $0 x a, n=5$. f. Colony formation assay after combination therapy of MHY1485 and Oxa. g. Statistical analysis of the colony formation assay, $\mathrm{n}=3$. cells were pretreated by MHY 1485 for 24 hours, then incubated with indicated concentration of Oxa for 48 hours. MHY1485, a mTOR activator. The Student's t-test for (c), one-way ANOVA for (e and g), all data indicate the mean $\pm S D, * p<0.05,{ }^{*} p p<0.01$. 
a

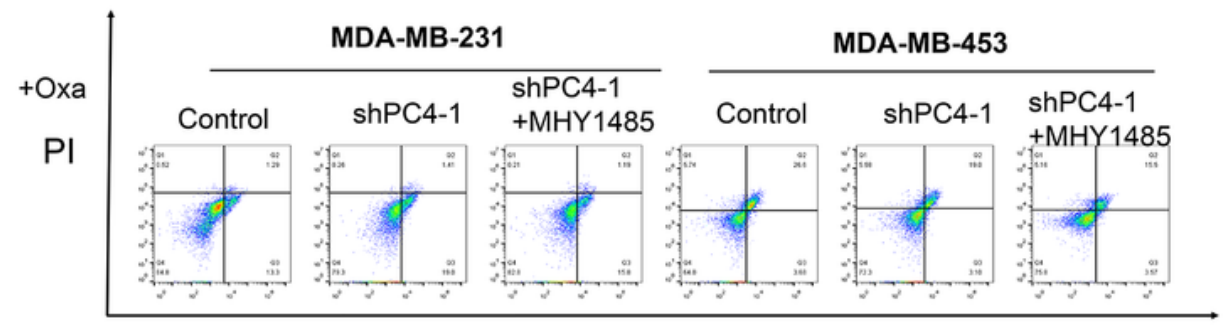

APC-Annexin V

C

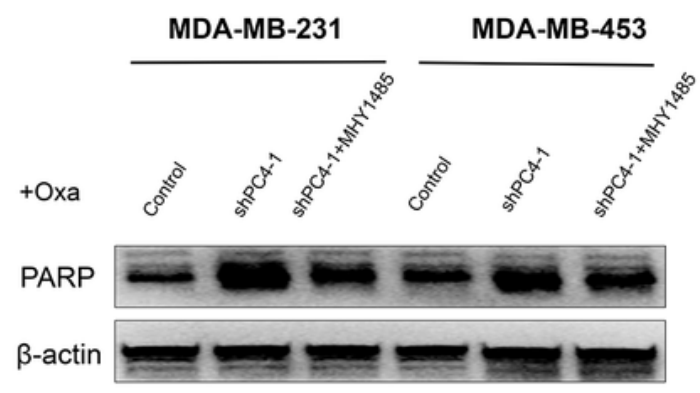

e

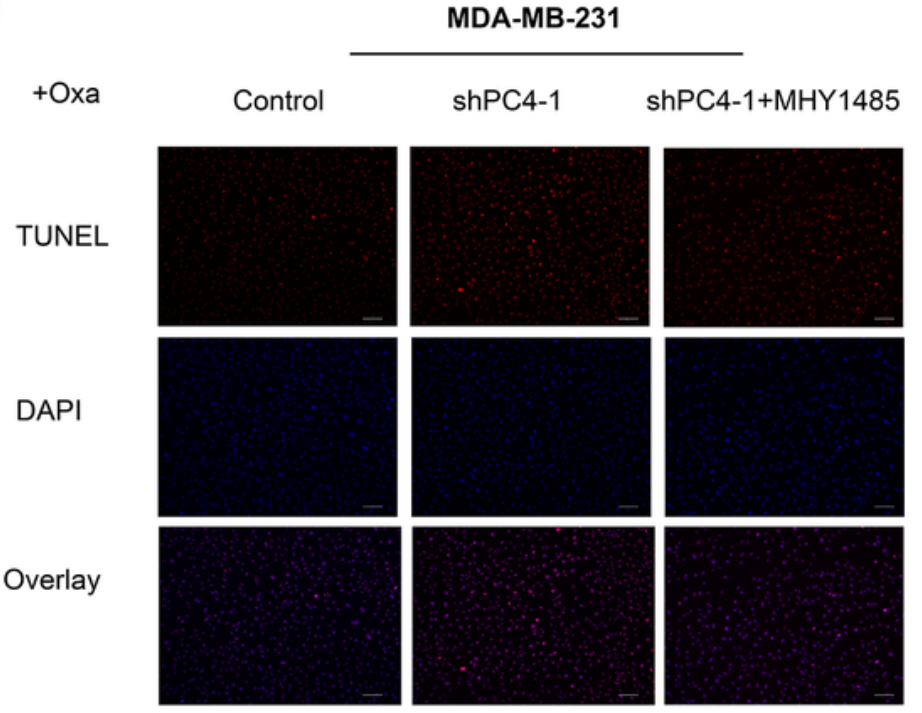

b
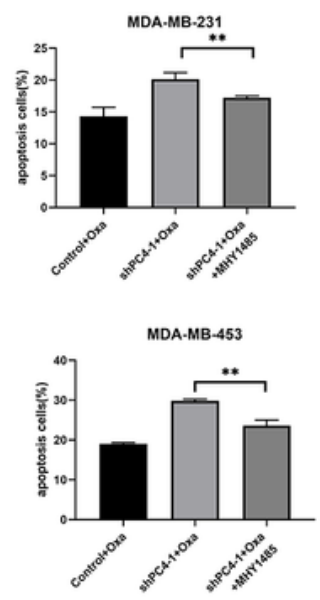

d
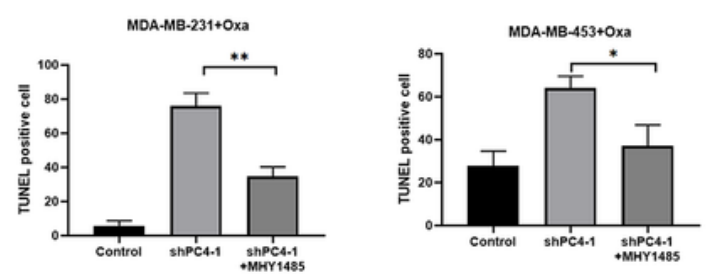

MDA-MB-453

Control

shPC4-1

shPC4-1+MHY1485
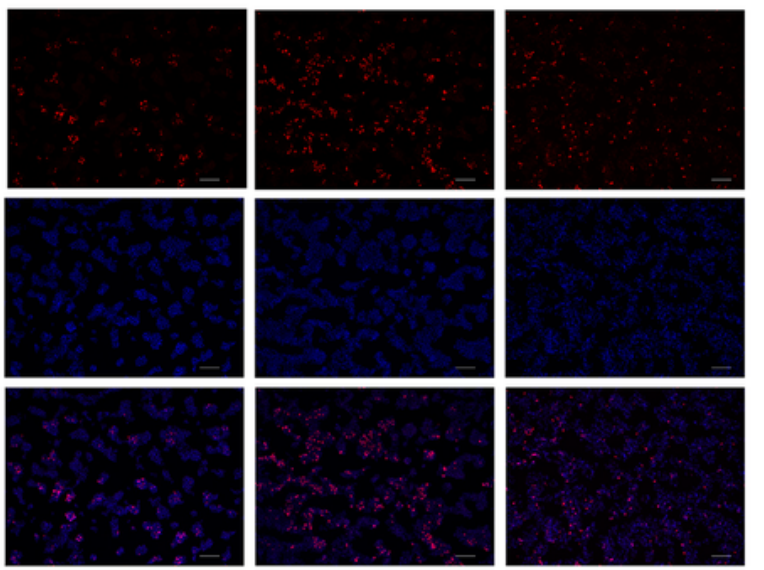

\section{Figure 5}

PC4 knockdown enhances the Oxa-induced apoptosis in TNBC cells by downregulating mTOR pathway a. Apoptotic cells (annexin V positive) was detected by flow cytometry 48 hours after combination therapy of MHY1485 and Oxa. b. Statistical analysis of apoptotic cells, n=3. c. Western Blotting analysis of apoptosis-related protein PARP. $\beta$-actin, the sample loading control. $d$ and e. Apoptotic cells were stained by TUNEL and analyzed using ImageJ, Scale bar, $50 \mu \mathrm{m} . \mathrm{n=3}$. For D-L, cells were pretreated by MHY1485 
for 24 hours, then incubated with indicated concentration of Oxa for 48 hours. MHY1485, a mTOR activator. one-way ANOVA, all data indicate the mean $\pm S D_{,}{ }^{*} p<0.05,{ }^{\star *} p<0.01$.

a

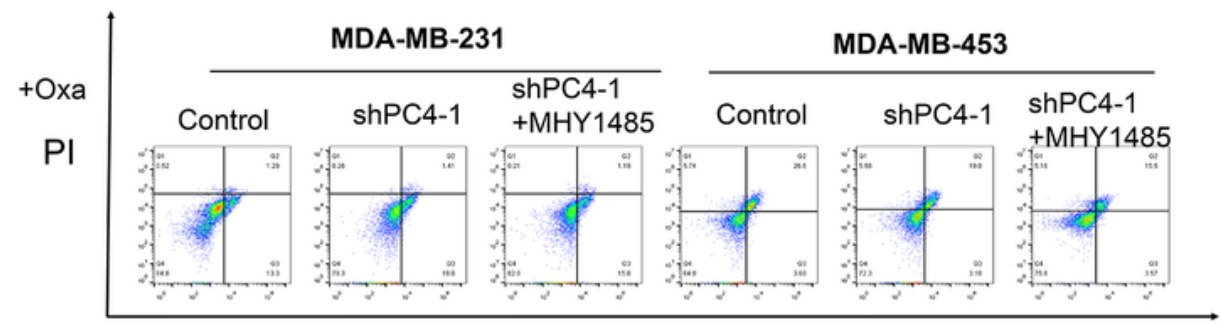

APC-Annexin V

C

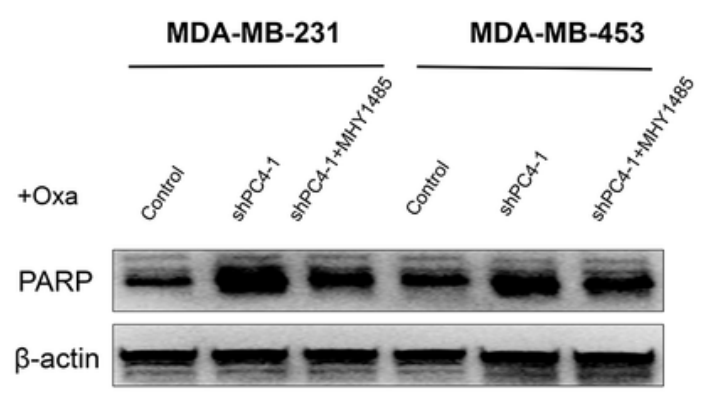

e

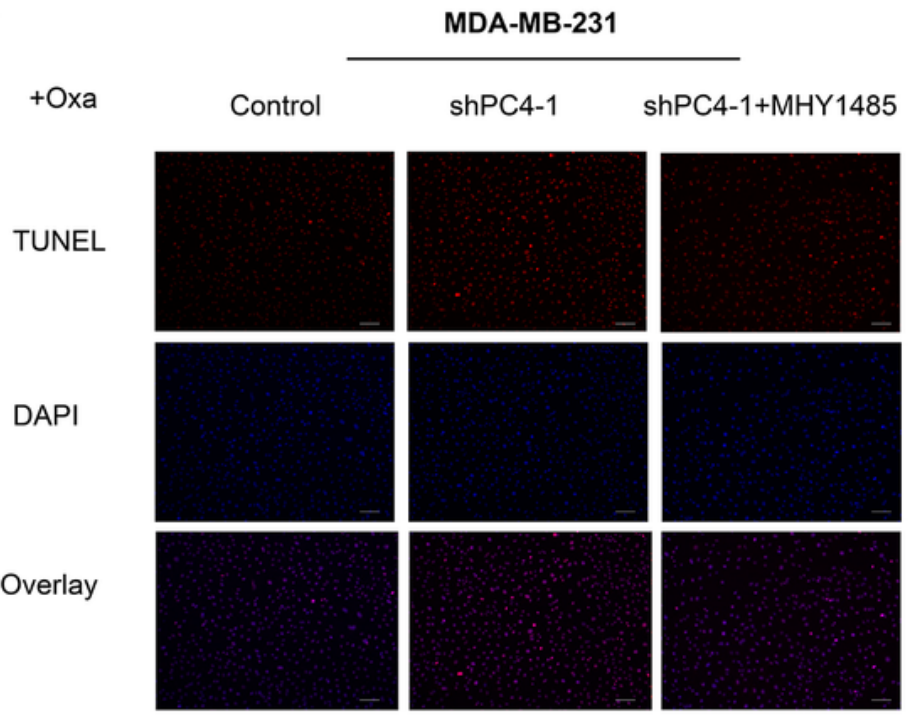

b
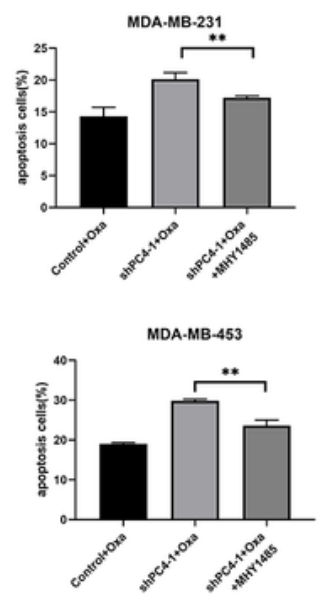

d
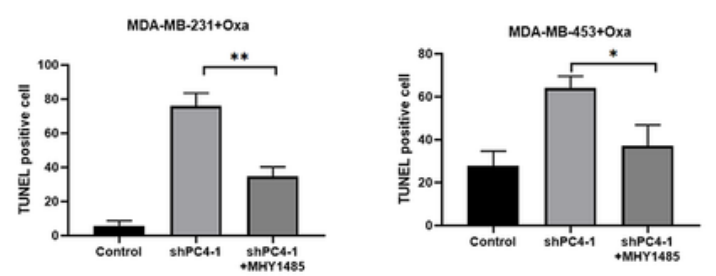

MDA-MB-453

Control shPC4-1 shPC4-1+MHY1485
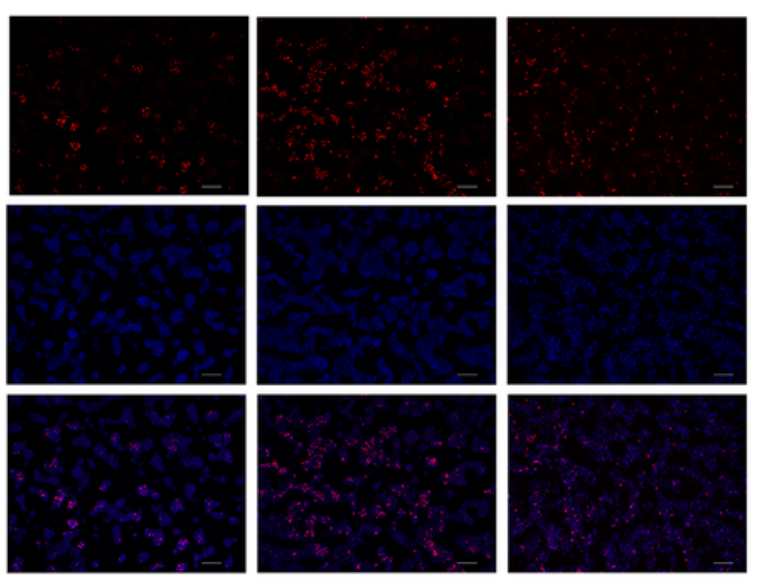

\section{Figure 5}

PC4 knockdown enhances the Oxa-induced apoptosis in TNBC cells by downregulating mTOR pathway a. Apoptotic cells (annexin V positive) was detected by flow cytometry 48 hours after combination therapy of MHY1485 and Oxa. b. Statistical analysis of apoptotic cells, n=3. c. Western Blotting analysis of 
apoptosis-related protein PARP. $\beta$-actin, the sample loading control. $d$ and e. Apoptotic cells were stained by TUNEL and analyzed using ImageJ, Scale bar, $50 \mu \mathrm{m}$. $\mathrm{n}=3$. For $\mathrm{D}-\mathrm{L}$, cells were pretreated by MHY1485 for 24 hours, then incubated with indicated concentration of Oxa for 48 hours. MHY1485, a mTOR activator. one-way ANOVA, all data indicate the mean $\pm S D_{\text {, }}{ }^{*} \mathrm{p}<0.05$, ${ }^{\star *} \mathrm{p}<0.01$.

a

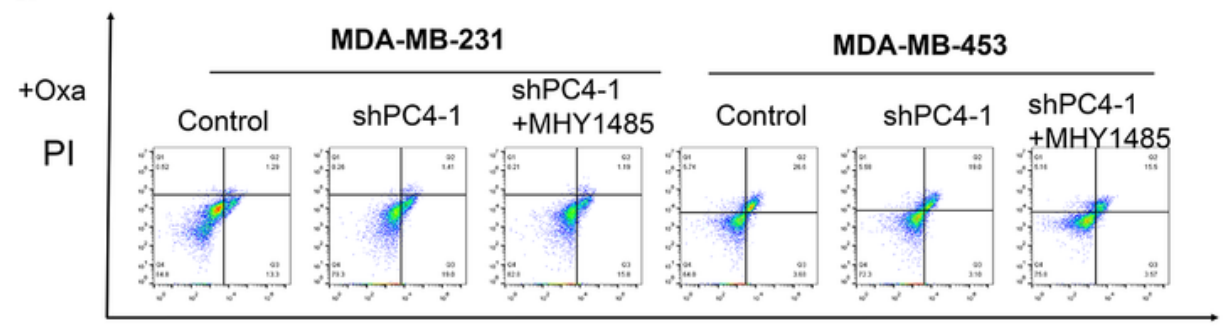

APC-Annexin V

C

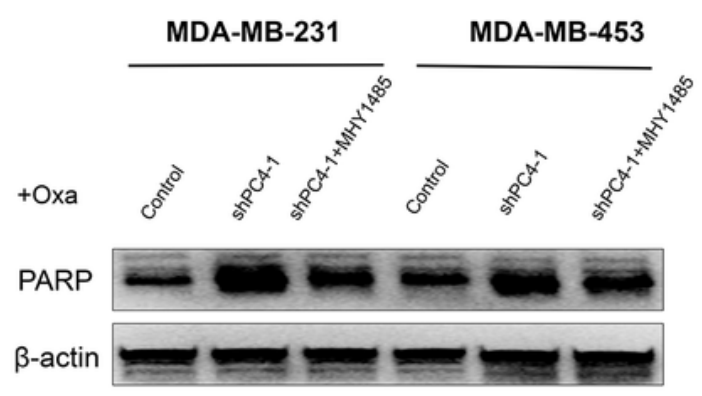

e

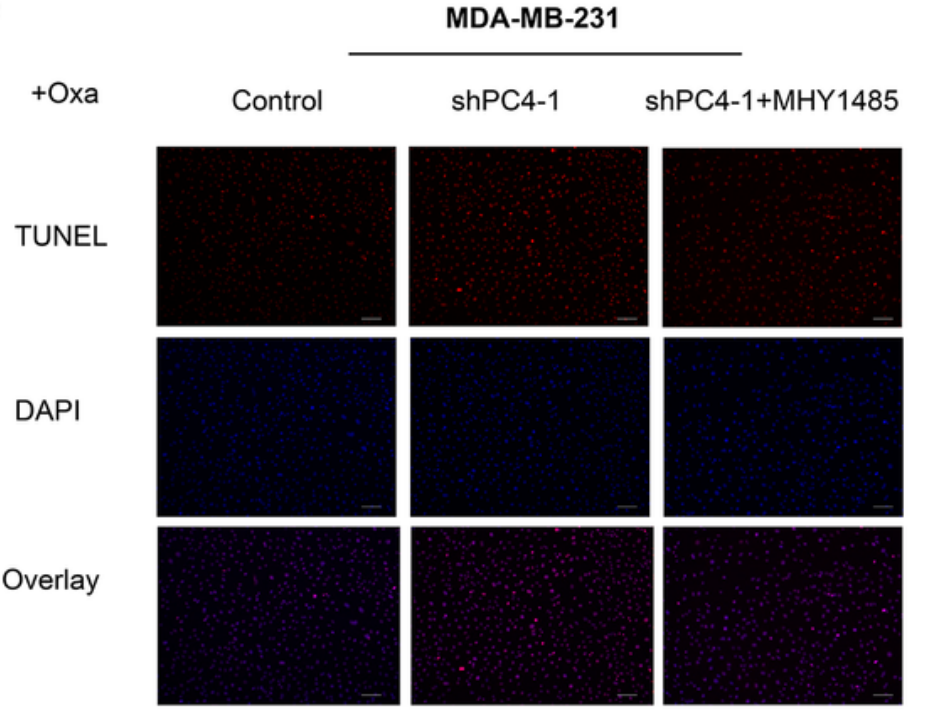

b
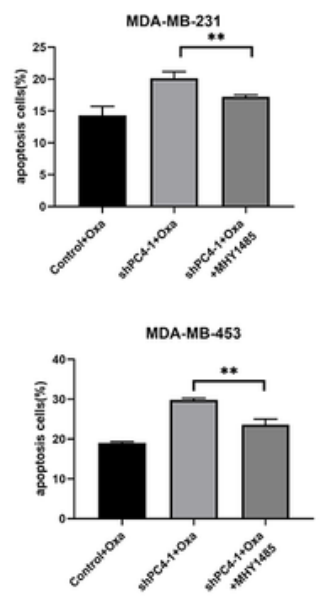

d
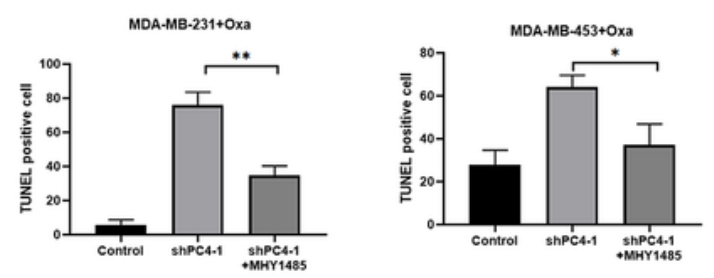

MDA-MB-453

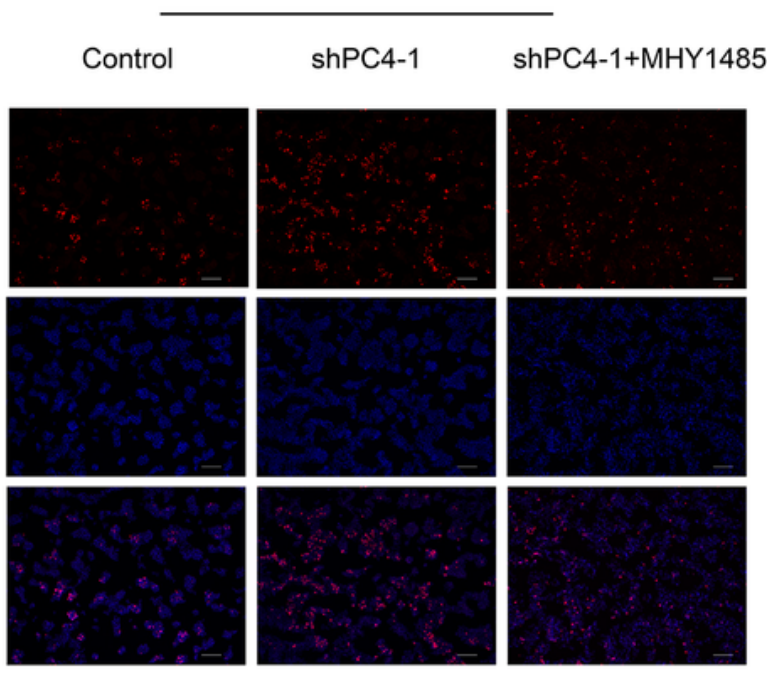

Figure 5 
PC4 knockdown enhances the Oxa-induced apoptosis in TNBC cells by downregulating mTOR pathway a. Apoptotic cells (annexin $\mathrm{V}$ positive) was detected by flow cytometry 48 hours after combination therapy of MHY1485 and Oxa. b. Statistical analysis of apoptotic cells, $n=3$. c. Western Blotting analysis of apoptosis-related protein PARP. $\beta$-actin, the sample loading control. $d$ and e. Apoptotic cells were stained by TUNEL and analyzed using ImageJ, Scale bar, $50 \mu \mathrm{m}$. $\mathrm{n}=3$. For $\mathrm{D}-\mathrm{L}$, cells were pretreated by MHY1485 for 24 hours, then incubated with indicated concentration of Oxa for 48 hours. MHY1485, a mTOR activator. one-way ANOVA, all data indicate the mean $\pm S D_{\text {, }}{ }^{*} \mathrm{p}<0.05$, ${ }^{\star *} \mathrm{p}<0.01$.

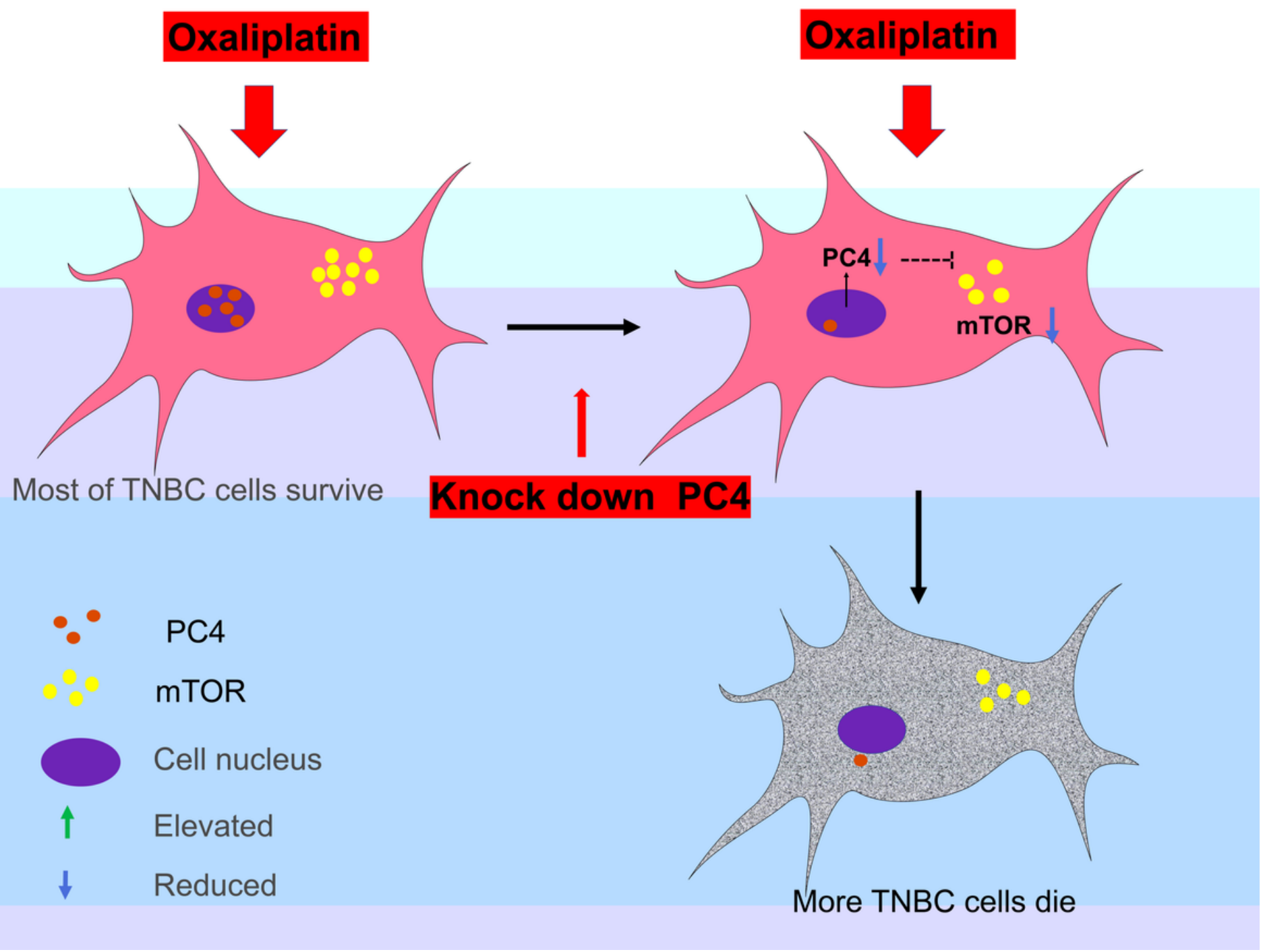

\section{Figure 6}

Schematic illustration for the potential mechanism of PC4 to TNBC' chemosensitivity for Oxa treatment. Knockdown of PC4 in TNBC cells enhances the sensitivity to Oxa by downregulating mTOR pathway. 

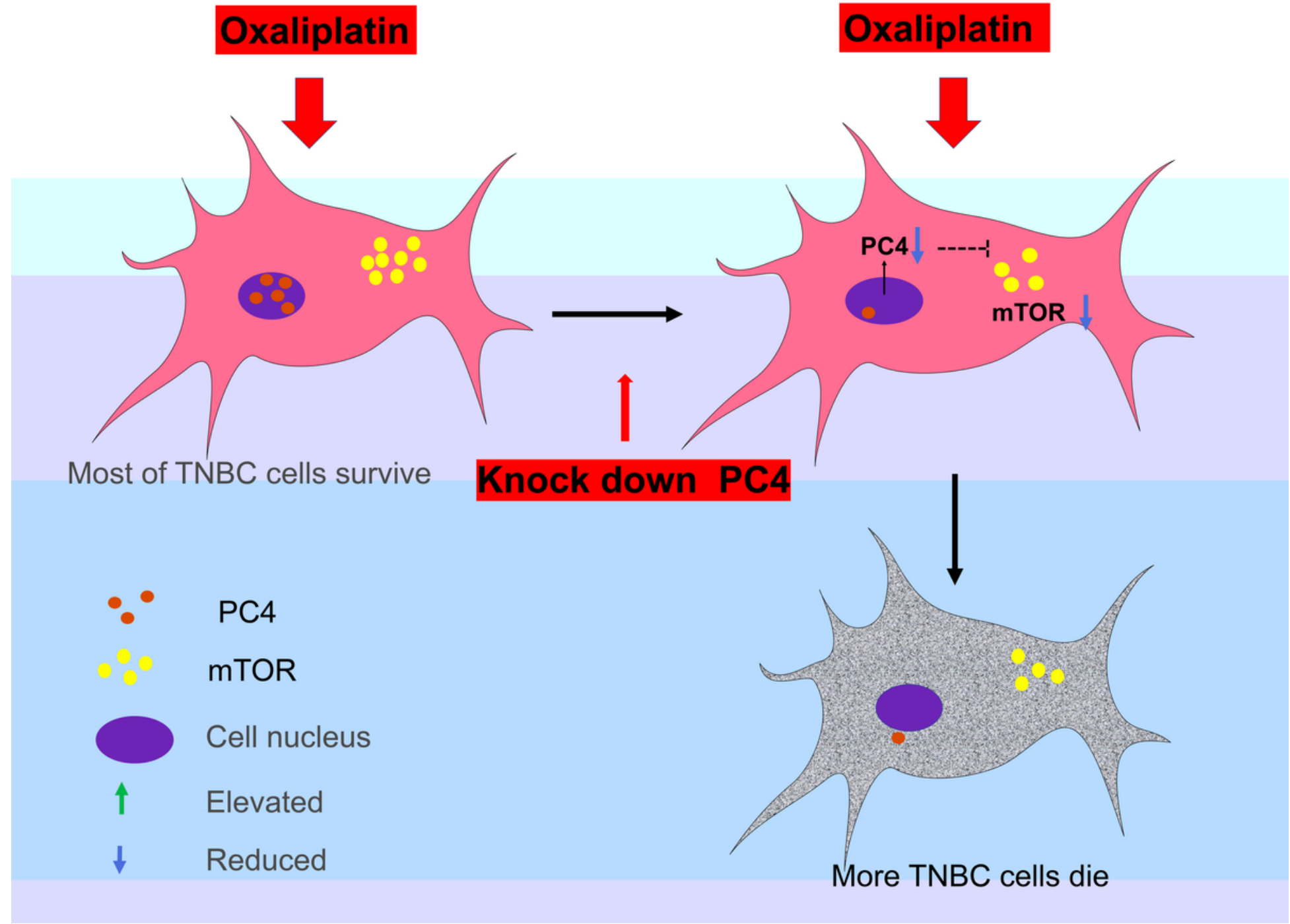

Figure 6

Schematic illustration for the potential mechanism of PC4 to TNBC' chemosensitivity for Oxa treatment. Knockdown of PC4 in TNBC cells enhances the sensitivity to Oxa by downregulating mTOR pathway. 


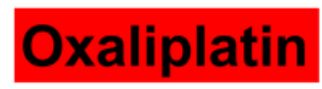

\section{Oxaliplatin}

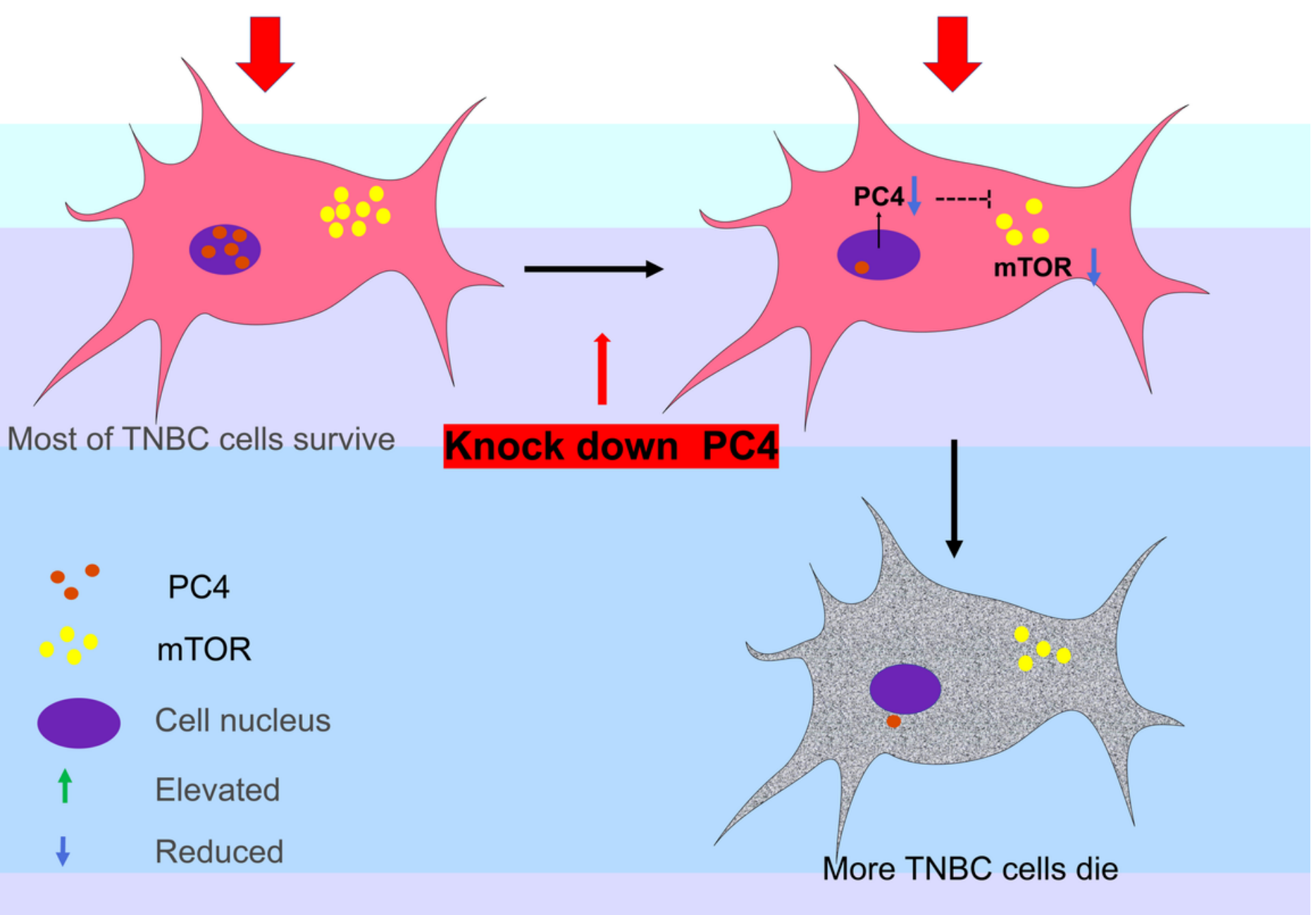

\section{Figure 6}

Schematic illustration for the potential mechanism of PC4 to TNBC' chemosensitivity for Oxa treatment. Knockdown of PC4 in TNBC cells enhances the sensitivity to Oxa by downregulating mTOR pathway.

\section{Supplementary Files}

This is a list of supplementary files associated with this preprint. Click to download.

- Supplementarylnformation.docx

- Supplementarylnformation.docx

- Supplementarylnformation.docx 